Portland State University

PDXScholar

$5-1-1970$

\title{
A study of the role of acrylic paints in the secondary and junior high school art curriculum
}

Alice Atkinson Benski

Portland State University

Follow this and additional works at: https://pdxscholar.library.pdx.edu/open_access_etds Let us know how access to this document benefits you.

\section{Recommended Citation}

Benski, Alice Atkinson, "A study of the role of acrylic paints in the secondary and junior high school art curriculum" (1970). Dissertations and Theses. Paper 623.

https://doi.org/10.15760/etd.623

This Thesis is brought to you for free and open access. It has been accepted for inclusion in Dissertations and Theses by an authorized administrator of PDXScholar. Please contact us if we can make this document more accessible: pdxscholar@pdx.edu. 
AN ASSRRACT OF THE MHESIS OF Alice Atkinson Benski for the Master of Arte in Teaching presented May 12, 1970.

Titles A Study of the Role of Acryic Paints in the Secondary and Jurior High Sehool Art Curriculum.

APPROVED BI MENEERS OF THE THESIS COMMITIEE:

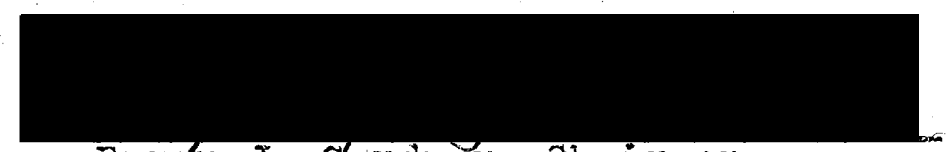

Byzen J. Gerdner, Chejman

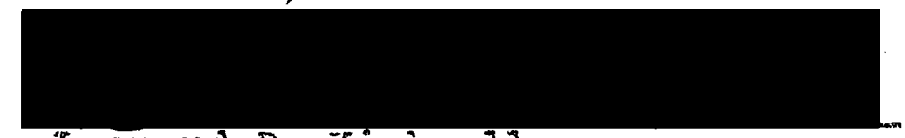

Leonard B. Kimbre1]

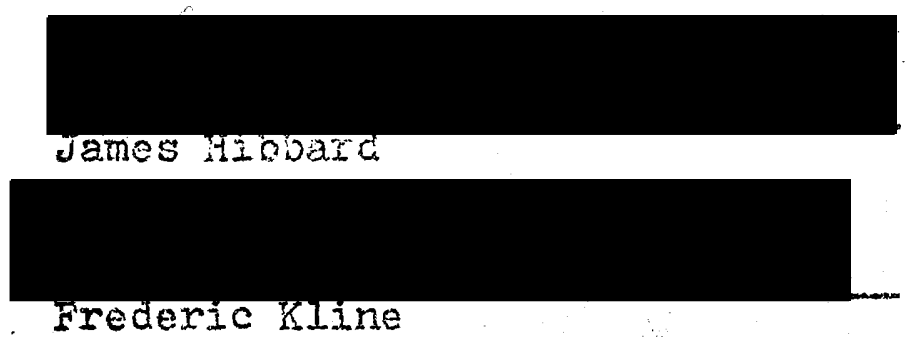

It was my purpose to study the role of acrylic paints and other products in the secondary high school and junior high school art curriculum in the area of painting and related activities and to malse a realistic evaluation of this medium. Because of its comparative newness, and because of a general lack of knowledge of and experience with it, I felt such a study would fill a need relative to the utilization of acryic products in the classroom. In preparation I read the material which wes available on painting with acrylics. The number of books 
published on the subject is limited. I talked with art teachers and found that mary had only a cursory acquaintance with acrylics or had not used them at all. With this background I became irvolved in as many aspects of the use of acrylics in the classroom as I coujd. A skeptic at first, I became increasingly enthusiastic as my work prom gressed. From my own experiences with acrylics, I devised some experiments which, for the most part, I took into the classroom and with which I involved students rarging from third grade to high school level.

After my own experiences with acrylics as both artist and teacher, it is my conviction that acrylics can be invaluable in the art curriculum, and that they can be most helpfuI in providing a significant contemporary approach to the fundamentals of painting and other techniques.

There are five chapters and an appendix in this thesis report. The first chapter provides an introduction to the acrylic products, with a brief summary of their development as a fine arts medium, their cost, handling characteristics and their advantages and disadvantages. The second chapter is concerned with the individual acrylic products and with equipment and supplies. Painting techniques and suggestions for the use of acrylics are discussed in the third chapter. Suggestions for additional uses in the related activities of collage, mosaic, printing, drawing, transparent design and other techniques are contained in the fourth chapter. 
In the fifth chapter I state my conclusions concerning the medium.

Photographs of student work and my work are included as a supplement to the text. A list of local suppliers and a list of manufacturers is included in the appendix, as well as photographs of my thesis paintings. 
TO THE OFFICE OF GRADUATE STUDIES

The nembers of the Committee approve the thesis of Alice Atkinson Benski presented May 12, 1970.

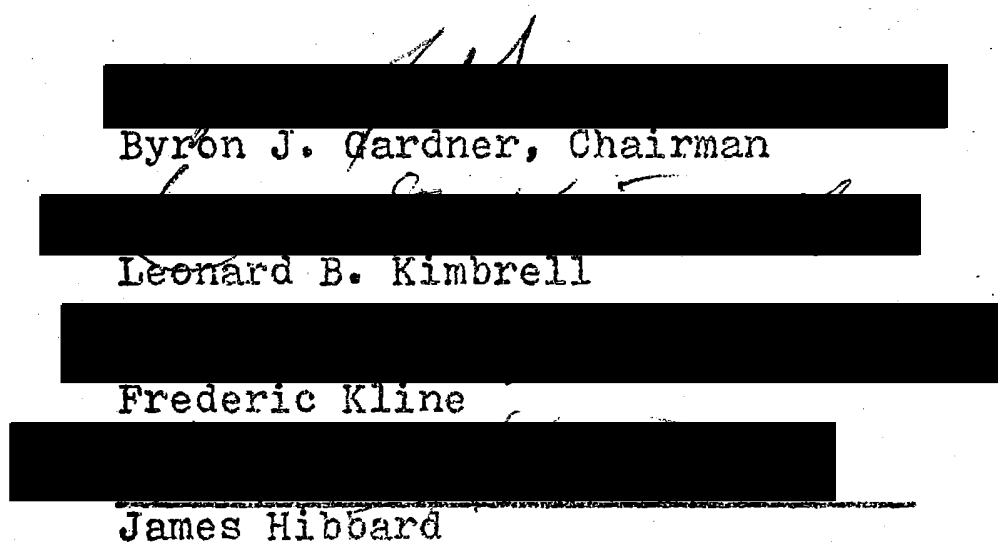

\section{APRROVED :}

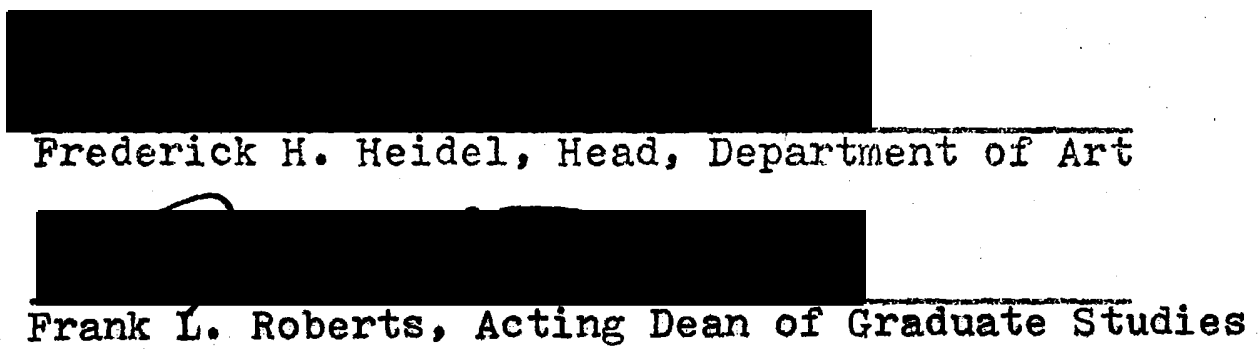

May 14,1970 
A STUDY OF THE ROLE OF ACRYIIC PAINTS

IN THE SECONDARY AND JUNIOR

HIGH SCHOOI ART CURRICULUM

by

AIICE ATKINSON BENSKI

A thesis submitted in pastial fulfjllment of the requirements for the degree of

MASTER GF ARTS

in

TEACHING

Portland State University

1970 
TABLE OF CONTENTS

PAGE

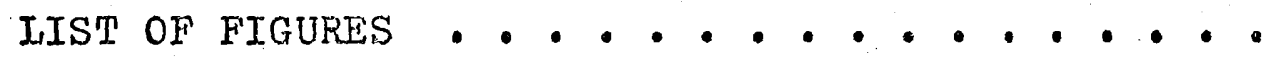

CHAPTER

I INTRODUCTION TO ACRYLICS . . . . .

Cost

Handling . . . . . . . . . .

4

Advantoges and Disadvantages . . . 6

II PREPARATION FOR PAINTING WITH ACRYIICS .

9

Equipment and Supplies . . . .

Acrylic Products and Pigments Brushes Palettes

Supports

II PAINTING WITH ACRYIICS $\cdot$. $\cdot$. $\cdot$.

Techniques •. • . . . . . .

Glazing

Scumbling

Impasto

Texture

Resist

Hard Edges

Finger Painting

Color Crayon

Chalk

Corrections

Mural Painting . . . . . . . .

Construction Painting . . . . . . 
CHAPTER

PAGE

IV ADDITIONAL CLASSROOM USES OF ACRYLICS • •

Collage . . . . . . . . . . .

Transfer Technique

Printing with Acrylics . . . . . .

Monoprinting

Collograph

Silk Screen

Raised Design on Block

Corrections

Drawing with Acrylics

Ink

Wet-on-wet

Linseed Oil Resist

Ink Wash

Fixative and Wash

Mosaic.

35

Transparent and Translucent Design . . 36

Miscellaneous Uses . . . . . . . 38

Sculptural Medium

Papier Mache

Picture Frames

slides

$\mathrm{V}$ CONCLUSIONS 


\section{IIST OF FIGURES}

FIGURE

PAGE

1 Three Dimensional Painting on Wood . . . 26

2 Construction-Painting .......... 26

3 Painted Wooder Block ... . . . . . . 27

4 Stabile of Wooder Blocks . . . . . . . . 27

5. Collage and Texture Block . . . . . . 30

6 Transfer Collage on Block . . . . . . 30

7. Value Study, Denise Hoskins . . . . . . 45

8 Value Studies, Steven Karlik, D. Hoskins . . 45

9 Transparent Color, Roger Iong . . . . . . 46

10 Transparent Color, Roger Iong . . . . . 46

11 Opaque Color, Tom Schierholz, S. Karlik . . 47

12 Opaque Color, Mimi Brodeur, Iisa Jennings . - 47

13 Limited Palette Leaf Study, Teresa Gerdes . . 48

14 Iimited Palette Ieaf Study, Susan Iair . . . 48

15 Iimited Palette Ieaf Study, Roger Iong . . . 48

16 Acrylic Iandscape, Cathy Pollock . . . . . 49

17 Acrylic Iandscape, Cathy Pinch . . . . . 49

18 Acrylic Landscape, Steven Karlik . . . . . 50

19 Acrylic Iandscape, Denise Hoskins ... . . . 50 


\section{CFIPRER I}

\section{INTRODUOIION TO ACRYLICS}

Since prehistoric times, when charcoal was used as pigment and animal fat as bjrder. man has used organic materials in his artistic development. Today many professional artists and students are substituting a man-made synthetic paint and medium for the organic media of the past. It is the intent of this paper to explore this medium in relation to the high school and junior high school art curriculum.

The syrthetic acrylic artists' meterials belong to a versatile family which includes the molded plastics such as Plexiglas, as well as plastics in solution used as binders and adhesives in a number of industries. Mexican muralists were pioneers in the use of synthetic paint as a fine arts medium in their search for bright colors which would stand exposure to the elements. As early as 1930 an Anerican artist, Leonard Brooks, used a synthetic resin paint in murals, but he mixed it with oils and it subsequently deteriorated. 1

The big surge in the development of acrylic paints

${ }^{1}$ Russe11 0. Woody, Jr., Painting With Synthetic Media (New York Reinhold, 1965), p. 30 . 
came after World War II. The earlier plastic products were unstable, brittle, affected by temperature changes and did not keep well. In 1953 a quick drying, durable non.. yellowing emulsion suitable as a commercjal binder for artists' colors was developed. Today, most of the well known manufacturers of artists materials include a line of acryic paints among their products.

In the synthetic emulsions, fine particles of plastic resin are suspended in watex; when the water evaporates, a clear, flexible filn remains. To this emulsion is acied the pigmentation. Pigments in synthetic paints are generalyy the same as those in oils and other artists colors, with the exception of a few which are not compatible with the synthetic base, and for these, synthetic substitutes were dereloped.

There are several different plastic bases for products used by painters. The commercially prepared plastic paints include acrylic resins, vinyl resins and a combination of both, known as co-polymers. The acrylic resins have become the most popular of the syrithetic paints of the market today and are referred to as synthetics, plastics, polymer temperas and acrylic paints, a.ll terns used synonomously. It is possible to manufacture one's own synthetic paints. Formulation for them is readily avallable ${ }^{2}$ and

Iawrence N. Jensen, Synthetic Painting Media (Englewood Cliffs, New Jersey, 1964), pp. 46-47, 94-95, 101-102. 
Gutiérrez and Roukes devote an entj.re chapter in their book to the making of plastic paint. 3 They caution that some of the materials are toxic and flammable and should be handled only by an expert with adequate workshop and equipment.

\section{I. $\cos T$}

A comparative price study established that there is little price differential among the better known brands of acrylics. The deternining factor in selection of most acrylic material would probably be personal preference or availability.

Considerable saving can be achieved by buying paint and medium in large size containers, and this is recommended if it is to be used in quantity. When using Iarge quantities, the use of a concentrated liquid colorant and acrylic house paint in conjunction with the acrylic artists' products will reduce costs. The polymer medium has many uses and should be purchased in quart or gallon size. This is the one acrylic product on which there is a great price variation among brands.

If a comparison of the prices of acrylic paint with oil paint is made, it should be noted that most acrylics are packaged in two ounce tubes and have over $40 \%$ greater volume than the standard studio size tube in which oil paint

3José Gutiérrez and Nicholas Roukes, Painting With Acrylics (New York: Watson-Guptill, 1966), pp. 30-55. 
is packaged.

\section{HANDLING}

\section{Mixing And Thinning}

All products within each manufacturer's line are compatible, and in the course of my experimental work with acrylics, the only reaction encountered in a constant intermixing of brands at random, was an occasional thickening of the paint. Although oj.ls and plastic paints should not be mixed together, the under painting for an oil paintjng can be done with acrylics. Bocour Artist Colors, Inc. markets an oil miscible synthetic paint under the Magna name. This is not compatible with the water base acrylics.

There are no fixed rules for proportions in mixing the acrylic colors and mediums. The student should be encouraged to experiment with various biends of medium and color. A slight thinning of color will result in a tempera like paint. A greater dilution of the paint with water results in a paint which is transparent. The only precaution in mixing mediurs and water is to avoid the use of too great a proportion of water, as the structure of the final dry film will be weakened.

\section{Control of Drying}

It is essential to have water on hand when working with acrylics. Water may be sprayed over both the palette and the painting occasionally to keep the paint from drying 
out. Brushing a coat of fuld strength medium over the dry painting surface before applying the color will retard drying to some extent. The gel medium dries more slowly than the polymer medium and can be used when slower drying is desirable.

A retarder is sold by several manufacturers, and some artists use glycol to retard drying. 4 we did not find it necessary to use a retarder, as the students were not handicapped by the fast drying qualjty of the acrylics. It is important to limit the amourt of paint placed on the palette to a quantity which can be used within the class period.

\section{Clean Up}

The best clean up measures are preventitive ones. This is true when working in any art medium. It is recommended that the student wear an apron or smock when he is working with acrylics.

If acrylic medium or color is spijled on work areas, floors or fabrics, it should be cleaned up immediately. It is much easier to remove while it is still water soluble than it is when it hardens. Washable fabrics should be rinsed in water at once, if possible. If the acrylic has hardened, or if water does not remove it, an acrylic remover, denatured alcohol or acetone may be used on some fabrics. If the acrylic base has been pigmented with color other than

${ }^{4}$ Gutiérrez and Roukes, po 124. 
acrylic, this must be taken into consideration in stain removal. If the garment is a valued one, a professional cleaner is recommended.

\section{ADVANTAGES AND DISADVANTAGES}

The acrylic artists' materials have many advantages over the conventional media. An important aspect from the standpoint of the ari teacher is their versatility. They are useful in collage, printmaking, drawing, mosaic, papier mâche' and three dimensional work, as well as in painting. Applications of color can range from transparent wash to heavy impasto, with many special effects possible. Another important advantage of the acrylics is the fact that they are non-toxic and non-flammable and that both thinning and routine clean up can be accomplished with water. However, acrylic products which have hardened are difficult to remove from fabrics and equipment.

The adhesive quality of acrylics permits extensive use of textures and additives, and the polymer emulsions do not yellow or becone brittle with age, as do the white emulsion glues.

Because acrylics protect and preserve the support, they can be used on a wide variety of grounds. They are alkali resistant, making them an ideal mural medium. The surface of a work done in acrylics is durable, non-fading, resistant to the elements and water resistant when dry. 
Applications of normal thickness will remain flexible when dry and both cloth and paper supports can be rolled without danger of the paint cracking.

The mediums have a greater permanent transparency than any other painting vehicle, with the exception of water. As a result of the clarity of the medium, colors have brilliance and luminosity. Colors are virtually the same when wet or dry, making color effects apparent while work is in progress.

Acrylics are fast drying, there is no variation in the drying time of the different colors, and overpainting can be done over applications of ordinary thickness within a matter of a few minutes. One color layer will not bleed into subsequent layers. While the fast drying quality can be one of the most valuable assets of the acrylic products, it can, in some instances, be a disadvantage. However, there are means for retarding arying and I feel that the advantages of quick drying far outweigh the disadvantages. Storage of student work is facilitated as it can be stored in limited space after a short drying period. Some polymer mediums have a tendency. to remain slightly tacky for some time, and if work is to be stacked, waxed paper or plastic wrap should be placed between the paintings.

Advantages from a cost standpoint are apparent in the use of acrylics. Water is less expensive than solvents and many inexpensive materials can be used as painting supports. 
The synthetic medium invites experimentation and by making maximum use of the acrylic products, the secondary and junior high school art teacher can offer a more diversified art program with fewer materials and for less cost than if the various traditional media were all stocked. 
CHAPTER II

PREPARATION F'OR PAINTING WITH ACRYLICS

I. EQUIPNENT AND SUPPIIES

Following is a list of materials for use in painting with acrylics. Not all are essentjal, but all will contribute to the convenience of handling. Some items are discussed in greater detail on the succeding pages.

1. Acrylic products:

$$
\begin{aligned}
& \text { polymer medium, gloss } \\
& \text { polymer medium, matte } \\
& \text { modeling paste } \\
& \text { gel medium } \\
& \text { varnish, gloss } \\
& \text { varnish, matte } \\
& \text { color } \\
& \text { gesso } \\
& \text { remover and solvent }
\end{aligned}
$$

2. Addj.tives such as sand, pumice, vermiculite

3. Brushes: hair, bristle, nylon, assorted sizes

4. Cloths for clean up

5. Eye dropper for adding water to paint

6. Glass jars or cans for water containers and paint storage

7. Knives: painting or palette

8. Palette

9. Popsicle sticks or tongue depressors for handling paint

10. Razor blades, single edge for scraping palette

11. Scouring pads for cleaning palette

12. Soap or mild detergent

13. Spray bottle or atomizer for misting water over palette and painting

14. Supports: Masonite, paper, cardboard, wood, canvas

15. Textural materials: sponges, netting, papers, fabrics. 
Acrylic Products

Polymer Medium. This is a milky white liquid which resembles Elmer's glue and which dries clear and colorless into a waterproof, flexible film. It is the most versatile of the acrylic mediums. In addition to its use in painting. it can be used as an adhesive for collage, mosajc and papier mâché, a vehicle for textural additives, a fixative, preservative, printing medium, varnish and even more. This product is available in either matte or gloss and by mixing the two, any desired degree of sheen can be achieved. Modeling Paste. The texture and color of this varies, depending upon the brand. It is a thick, paste like product, generally off white in color. It can be used as a thickening agent and color extender, a binder for additives, in ground preparation and in texture and impasto techniques. It is useful as a filler and adhesive in restoring three dimensional objects.

Gel. This product is the slowest drying of the three acrylic mediums. It varies among the brands from a gelatinous material resembling vaseline to a milky white, cold cream like substance. It has greater adhesive qualities when wet than the polymer medium, and is preferable to it when adhering three dimensional materials to a support. It is also useful in creating impasto and textural effects. Varnish. Acrylic varnish is a milky liquid which dries clear. It is not manufactured by all companies as 
some recommend the use of polymer medium as a final painting varnish. It is not essentjal to varnish an acrylic painting, however, varnishing does allow for adjustment of the final degree of sheen and provide a protective surface. At least one manufacturer is marketing a spray acrylic varnish at this time.

Gesso. The synthetic gesso is a quick drying liquid primer consisting of an acrylic emulsion base with titanium White pigment. It does not deteriorate and can be stored indefinitely in a tightly closed container. one undiluted coat is normally sufficient for a protective seal, however, several coats will assure a smoother surface. It can be used as a ground under most media. A satisfactory gesso can be improvised by mixing white tempera with polymer medium in approximately equal amounts.

Color. Each major manufacturer produces approximately thirty or more tube colors in acrylics, comparable in chromatic range to oil colors. They are packaged in tubes and jars; sizes range from the studio size tube, through the eight ounce, pint and quart sizes, with gallon jars available in some lines. As a rule, the tube colors are of a heavier consistency than the jar colors.

To avoid evaporation and hardening of the paint, the container rims should be wiped clean and caps replaced immediately after use. Hot water will loosen a stubborn cap or Iid. 
A suggested list of colors for the high school painting student might include the following:

Red: cadinium light and medium

Yellow: cadmium medium, yellow oxide (ochre)

Blue: cobalt; ultramarine, cerulean

Green: chrome oxide, permanent, terre vert

Brown burnt sienna, raw sienna, burnt umber, raw umber

Black, Mars

White: titanium.

Other Pigments For Use With Acrylic Mediums. There

are several alternatives to using the acrylic paints. Dry pigments, liquid colorants, jiquid and dry tempera and other coloring agents such as inks and dyes may be mixed with the polymer mediums.

When mixing dry tempera with polymer medium, it will blend more evenly if it is first worked into a thick paste with a small amount of water and a few drops of liquid detergent, and then mixed with the polymer medium. Color can be prepared in this manner in advance of use and stored in tightly closed glass jars, but the quantity should be limited to an amount which will be used within a few weeks. We found that paint mixed from the dry tempera had a tendency to be slightly coarse in texture, but satisfactory for some work.

Acrylic base house paints, particularly white, black or charcoal gray, and the tint base are useful. These can be colored with the liquid colorants or tinted with acrylic artists' colors.

Another successful combination is colored chalk and 
polymer medjum. We used the chalks in a painterly fashion on a prepared surface and brushed the polymer medium over them. The chalk dissolves and a luminous surface emerges. The medium could be sprayed over the chalk, if desired. Remover And Solvent. The acrylic remover is useful in removing hardened acrylic products from brushes and other equipment and may be used on certain fabrics, but should be tested first. This solvent is toxic and flammable and should be handled with caution. In adaition to the commercial acrylje remover, denatured alcohol and acetone will dissolve some hardened acrylic.

\section{Brushes}

Most art classrooms have on hand brushes which can be used with acrylics. Nylon bristles resist the abrasive quality of acrylics better than the natural bristle brushes and are recommended for most work. Inexpensive nylon varnish brushes from the hardware or paint store are useful. The soft bristles of water color brushes are useful in achieving a smooth surface free from brush marks.

Brushes will last indefinitely when properly cared for. They should be immersed in water before being dipped into the paint and kept in water when not in immediate use. When the work is finished, the brushes should be rinsed at once in water and washed in soap or mild detergent.

\section{Palettes}

An acrylic palette should be smooth and non-absorbent. 
Formica, plastic egg trays, a strip palette designed for use with acrylics, aluminum dinner trays, or even a piece of heavy cardboard sealed with acrylic medium will serve satisfactorily. Acrylic paint left on the palette will dry out before the next class session, so no attempt should be made to save it for future painting. If the student will use any paint which night be left on the palette at the close of a painting session to paint on papers of various weights and textures, he will soon have a store of colored papers from which to draw for collage and design needs. When areas of color have dried on a palette, these can be lifted off by soaking them in water and then set aside to be used for surface enrichment in painting or collage.

Palettes are easily cleaned while the paint is still. moist by wiping off the excess paint and rinsing in water. Once paint has hardened on a palette, it can be loosened by soaking in water and scraping with a single edge razor blade, or by dissolving it in acrylic solvent. The simplest solution is for the student to use a disposable strip palette.

\section{Supports}

Almost any surface which is non-oily and has a degree of porosity can be considered as a painting support. A glossy surface should be sanded or roughened in order to insure better adhesion.

Priming can be done with any of the synthetic mediums, however gesso or polymer medium are usually used. A commer- 
cial acrylic house paint is satisfactory. The support can be left untreated and the acrylic paint itself will provide a protective coating. An untreated, absorbent surface will soak up a great deal of paint, however, and is not recommended unless it is used for special effect.

Much of the work done with acrylics can be accomplished on paper supports. Any paper or fabric which lacks body can be adhered to a rigid support with polymer medium. Papers can be stretched, but taping or clipping to a board is sufficient in most cases, as they do not have as much tendency to buckle with acrylics as with other water base paints. Priming the paper with polymer medium will aid the flow of color and minimize buckling. A coat of polymer medium on the back will aid in keeping it flat. An acrylic painting on paper can be varnished and will be waterproof enough to be wiped with a damp cloth, and soil resistant enough to be framed without glass.

Canvas can be used stretched or unstretched. It can be painted and then stretched. Canvas stretched over a three dimensional wooden frame offers an approach which is suitable for acrylic paints.

For a rigid painting surface, consider Masonite, Upson board, wood and plywood. Untempered Masonite is preferable to the tempered, as the paint will bind more satisfactorily without sanding. Buckling of rigid supports can be prevented by gluing strips of one by two lumber to the edges of the back with modeling paste. A coat of priming medium 
applied to the back as well as the front will also help prevent buckling.

A shaped, three dimensional painting surface can be fashioned from fiberglass cloch and polyester resin. This can be formed over a cardboard, wooden, clay or papier mâché mold.

In our acrylic experiments we found wooden blocks to be versatile painting supports. Our blocks were sawn by a local lumber yard and the four inch size cost less than eight cents each. Larger sizes can be constructed from plywood, or a well constructed cardboard box can be substituted. Holes can be drilled in the blocks and a dowel run through several of them to make a stabile, or screw eyes can be inserted for hanging.

Acrylic paint and mediums can be used on plaster, cement, unglazed tile, masonry and mortar. These surfaces should be clean and free from loose particles before applying a coat of polymer medium. This should be followed by several coats of gesso. 
CHAPTER III

PAINTING WITH ACRYIICS

It is impossible to equate acrylics with the nore familiar painting media such as oil, tempera and water color. Acrylics invite an experimental and exploratory approach because of their versatility. Rather than being used in imitation of other media, they should be exploited for their own distinctive qualities. The suggestions offered here will give the reader an idea of the wide range of possibilities.

\section{TECHNIQUES AND SUGGESTIONS FOR PAINTING}

\section{Opaque To Transparent, A Painting Sampler}

No other painting medium offers such great variety in application as the acrylic medium. Effects from opaque impasto to a transparent wash can be achieved with ease. A series of introductory experiences will familiarize the student with their working qualities, and help him to better realize their possibilities.

Before a student actually begins to paint with acrylics, it is a good idea to instruct him in the nature of the medium and how it differs from paints he may have used. If the fast drying quality is explained, along with 
the importance of keeping the brushes moist and limiting the amount of paint on the palette, their painting experiences can be very satisfying.

After a verbal introduction, the student should experiment with the colors and the various mediums. The first step is to paint an area of pure color. For maximum brilliance, this should be done on a white ground. Mix small amounts of color with each of the following gel, gloss medium, matte medium, modeling paste and gesso, painting an area with each. Gradualiy add a grater proportion of medium to the color and small amounts of water, if desired, until the mixture becomes transparent. Iet the student build upon this by experimenting with other techniques discussed here.

Experiment with combinations of transparent washes, one over another, noting the effect of one color upon another. Brush transparent washes onto a non-absorbent ground, gradually increasing the proportion of color to medium, until both translucent and opaque effects have been achieved.

- Mix color to the consistency of a transparent wash. Instead of brushing it on as a wash, apply it with short brush strokes allowing them to overlap. Vary the degree of transparency at times, allowing the color to become translucent. Continue to brush on color, one layer over another, and a luminous, almost opalescent surface will emerge. 
Flow transparent and translucent washes onto an absorbent, untreated canvas in generous quantities, noting the effect. Contrast this with color flowed onto a prepared canvas.

Underpaint a support in opaque polymer colors directly from the tube. With a limited palette, establish pattern, direction and value. Allow this to ary and brush over it with a series of glazes in various colors, some complementary, some analogous.

\section{G]azing}

Acrylics are well suited to glazing. Rapid drying makes experimental work practical and the clarity of the mediums gives brilliance to the glaze. Rich effects can be obtained by applying a number of coats of clear or colored glaze over an area. Use either gel or polymer medium.

The use of white in glazing mixtures, except for special effects, should be avoided, as the white pigment cuts down on the transparency of the glaze.

Glaze sheets can be made by pouring polymer medium, with or without color, onto a non-absorbent surface. When dry, the sheet can be lifted off and applied to a painting surface with polymer medium.

A crazing effect can be achieved when acrylic color glazes are used with oil glazes. Apply an oil glaze over a dry acrylic painting. Before it has dried completely, 
wipe off the excess. Over this apply a glaze of acrylic medium mixed with a small quantity of water. Because of the difference in drying time between the two materials, the surface will craze as the oil dries.

Scumbling

The fast drying quality of acrylic paint makes it useful in the scumbling technique. Ioad a stiff brush or a palette knife with paint of a heavy consistency and drag it across the dry surface of a painting. The color deposited can be effective in enhancing the painting surface or in modifying the color.

\section{Impasto}

Impasto of any great thickness should be done on a rigid support and should be built up gradually in several layers rather than in one very thick application. The textural build up can be accomplished with or without color. It is more economical with either gel or modeling paste, but can be done with pure color. Gesso lacks the resilience of the polymer mediums and should be blended with medium for greater flexibility, if used. An impasto of pure gel will dry clear and can be left uncolored over colored areas, can be glazed for luminosity or can be painted with opaque color.

Impas to may take hours to dry, depending upon its thickness. If cracks develop in the impasto, they can be 
filled with gel or modeling paste and will remain sealed.

Texture

There are several ways in which to incorporate texture into a work. It can be added to a medium and brushed on as paint; it can be sprinkied onto a wet painting ground or it can be cut or pressed into a surface.

Texturing agents such as sand, sawdust, marble dust, vermiculite or other material can be added to any of the mediums. Soaking additives in a solution of polymer medium and water before blending them into the vehicle will facilitate distribution and result in a more flexible surface when dry.

Additives can be sprinkled directly onto a wet surface but for greater permanence, should be given a coat of medium after they have dried.

When additives are used, they can be left their natural color, colored before application, or painted after they have dried on the support. Great subtleties of color are possible when natural materials are left uncolored.

Modeling paste is extremely useful in texturing. When applied to a rigid support in rairly thick applications, it can be combed, scratched or otherwise shaped. Impressions can be made in a partially set up ground by pressing textured materials into it and lifting them off. When modeling paste has hardened, it can be cut, carved or sawed for textural effect. 
Resist

Resist techniques can be used with either the transparent or opaque appljcation of color. Experiments can include work with rubber cement, wax crayon, masking tape, paper blockout or other resist material.

\section{Hard Edges}

There are several ways in which to achieve hard edges. Masking tape can be used to establish the edge of the form. painting along the edge. Another techniques involves brushing polymer medium along the edge of the tape, when the medium dries and the tape is removed, there will be $a$ slightly raised edge to serve as a guide. When working on a gessoed surface, the line of the edge may be incised in the gesso as an aid in achieving a straight line of color.

Finger Painting

For finger painting use polymer medium or gel with the acrylic color or with liquid or ary tempera.

\section{Acrylic With Colored Crayon}

Acrylic glazes applied over heavy applications of colored crayon can result in a jewel like surface effect. Keep the glazes transparent and try them in related and contrasting colors. 
Acrylic With Chalk

Cover the painting surface with colored chalks used in a painterly fashion. Build shapes, blend colors, use linear accents and apply the color generously. over the chalk brush polymer medium. The medium will dissolve the chalk and a Iuminous surface will emerge. Subsequent layers of chalk can be applied when the first layer has set up, brushing each time with the medium to set the chalk. The medium can be sprayed on if desired.

\section{Corrections}

Corrections and adjustments can be made even when working transparently by painting out an area with opaque white or color. When working on paper, a patch of the same type of paper can be torn to size and adhered to the ground with color or medium.

\section{MURAL PAINIING}

The acrylic medium is the most satisfactory mural medium for use in the school art program. It may be used for indoor and protected outdoor murals, however, no paint is totally impervious to the elements and the durability of an acrylic mural is contingent upon the amount of exposure as well as upon the proper preparation of the ground. Murals can be done on plaster, masonry, wood, paper or hardboard. Untempered Masonite is an excellent support. It can be adhered to another surface for installation if 
necessary. The surface should be given at least two coats of gesso before painting. If the gesso is thinred, it should be with medium rather than water, for added strength. The masonry and plaster surfaces must be clean, free from cracks and loose particles; all surfaces must be grease and dirt free.

The surface of a mural can be varied with the use of impasto, texture and gloss variations. High and low relief can be used. The mediums will serve as adhesive and sealer. Give a completed mural several coats of polymer medium or varnish when finished. If it is placed outdoors, revarnish it every year or two.

A durable painting medium can be mixed for an outdoor mural by combining polymer medium and water with cement. Follow manufacturer's instructions for proportions in mixing the cement, but use at least one part medium to three parts water for the 1iquid. This can be colored as it is mixed or painted when dry. The eupport for this type of mural must be sturdy and the surface should be covered with hardware cloth or metal lath for better holding. This usage is discussed in detail in Synthetic Painting Media. 5

\section{CONSTRUCTION PAINTING}

These can be assembled from pieces of Masonite and 5ensen, pp. 74-76. 
board mounted on a Masonite support. Stock corner molding used as framing material will provide a box like support for the backing. Sometimes small pieces of finished lumber can be salvaged from a planing mill, catinet shop or the school woodshop. Cut the Masonite to the desired overall size and either sand or bevel the edges of the smaller pieces which are to be incorporated into the design. When the design is worked out and the colors decided upon, the individual pieces should be painted before assembling. Small blocks of wood can be used behind the mounted pieces to give a further three dimensional effect. Use either gel medium or modeling paste as the adhesive. Paint the pieces so that the design flows over the entire surface in a continuous pattern or paint the smaller pieces to create a contrasting area. Some pieces or areas can be textured for contrast. 


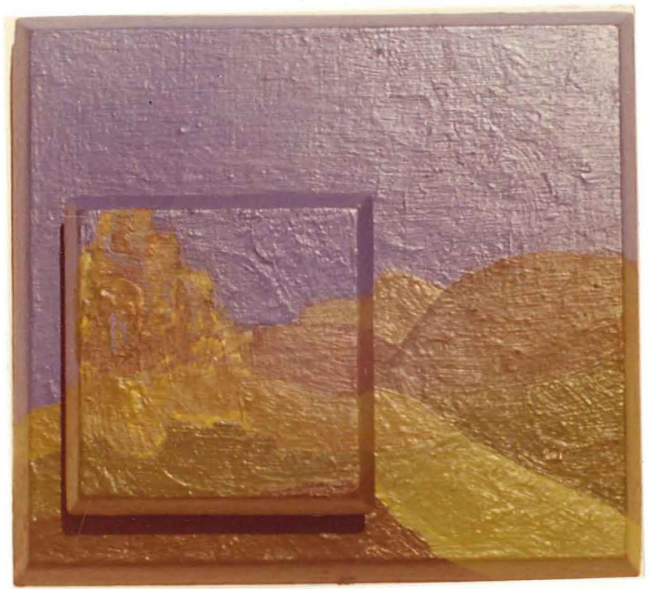

Figure 1. rhree

Dimenstonas painting on wood $6 \frac{1}{2} x^{3} \times 7^{30}$

Figure 2. Construction Painting $10^{10} \times 14^{\circ 0}$

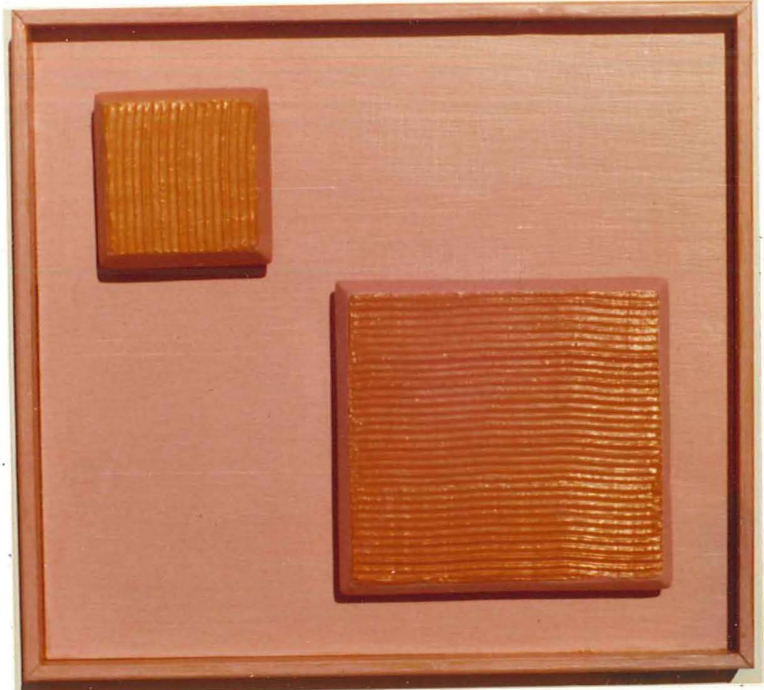




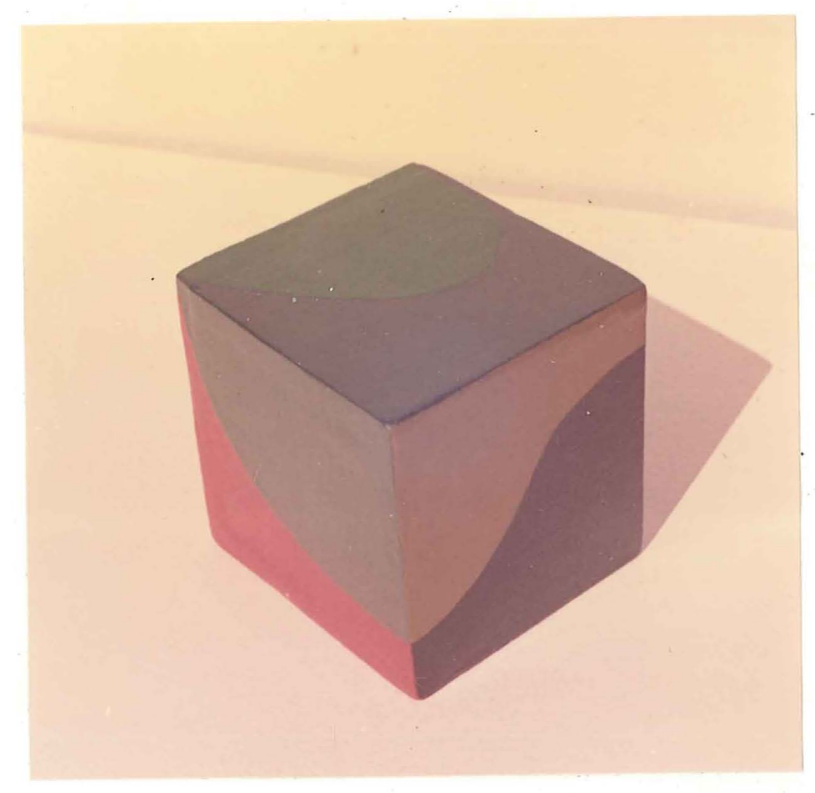

Figure 3. Painted Wooden Block $40 \times 44^{n} \times 4 \frac{13}{2}$

Fisure 4. Stabile of Wooden Blocks height $13^{\circ}$

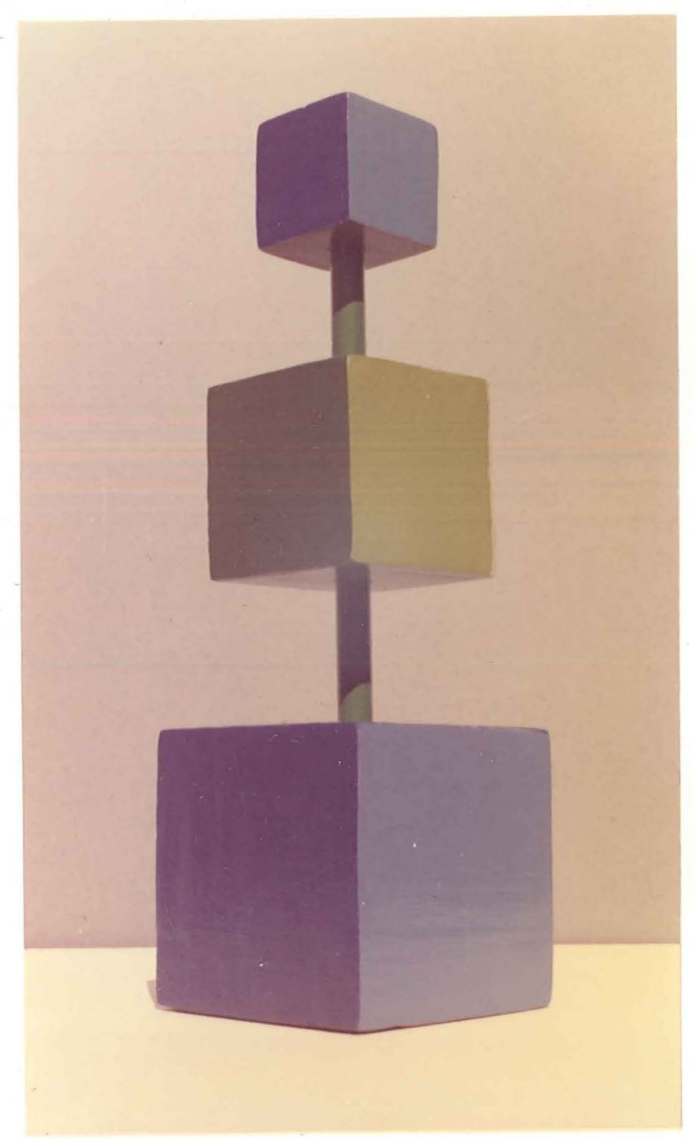


CHAPTER IV

ADDITIONAI CLASSROOM USES OF ACRYLICS

I. COLIAGE

Acrylic mediums are ideal for use in collage because of their clarity and ahesiveness. They are superior to the white glues for mounting materials as they are nonyellowing, permanently flexible and form a protective coating over the collage. Gel is more effective as an adhesive for heavy or bulky items than the polymer medium. The support for collage should be rigid if the additives are heavy, and the surface should be givern a coat of mediun before application of collage material.

There are many suitable materials for collage: paper, wood, fabric, metal and plastics, as well as granular, fibrous and natural materials.

Papers can be crushed or crinkled and coated with medium, allowed to dry and applied to the support. They will be permanently textured and can be painted before or after application.

Iightweight fabrics soaked in polymer medium or in medium mixed with gesso can be shaped and applied when dry. Acrylic paint thinned to a free flowing liquid can be brushed over fabric as a dye. 
Porous papers and fabrics can be adhered to a support by brushing the polymer medium diluted with water over the material which has been positioned on the support. As the medium penetrates the naterial, it will adhere.

\section{Transfer Technique}

An unusual transfer technique can be accomplished through the use of polymer medium. Several coats of the medium should be brushed on the material to be transferred, such as a newspaper or magazine photograph, allowing each coat to dry before the next one is applied. After several coats have been applied and dried, soak the paper in a tray of water for a few minutes and then carefully peel the paper from the back of the printed material and the printing ink image will remain intact on the polymer film. It can then be adhered to the painting surface with a coat of medium. When the paper is first removed from the back, the image on the film will appear milky, but it will dry clear.

\section{PRINTING WITH ACRYIICS}

Acrylics are useful in some printing technjques, particularly collograph and monoprinting, but their fast drying quality and their adhesiveness must be taken into consideration. The fact that they are water soluble yet dry water resistant is advantageous. 


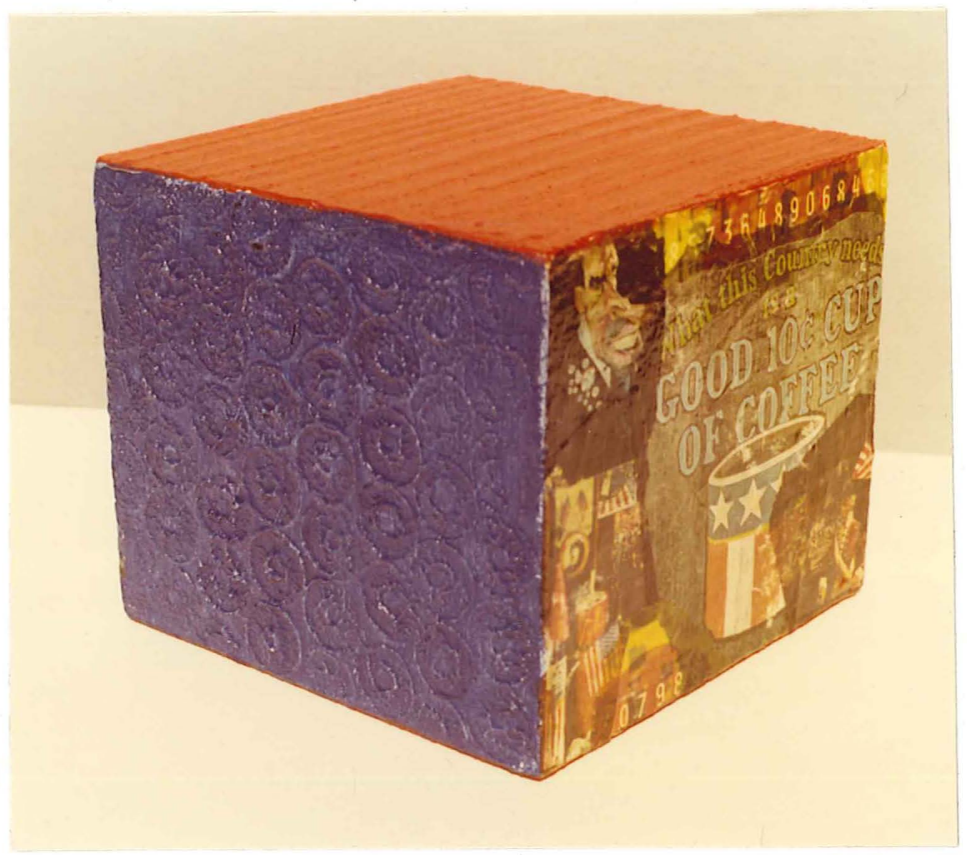

Figure 5. College ard Texture Block

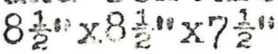

Figure 6. Transfer Collage on Block

$7 \frac{\frac{1}{2}}{2} \times 8 \frac{1}{2} " 1$

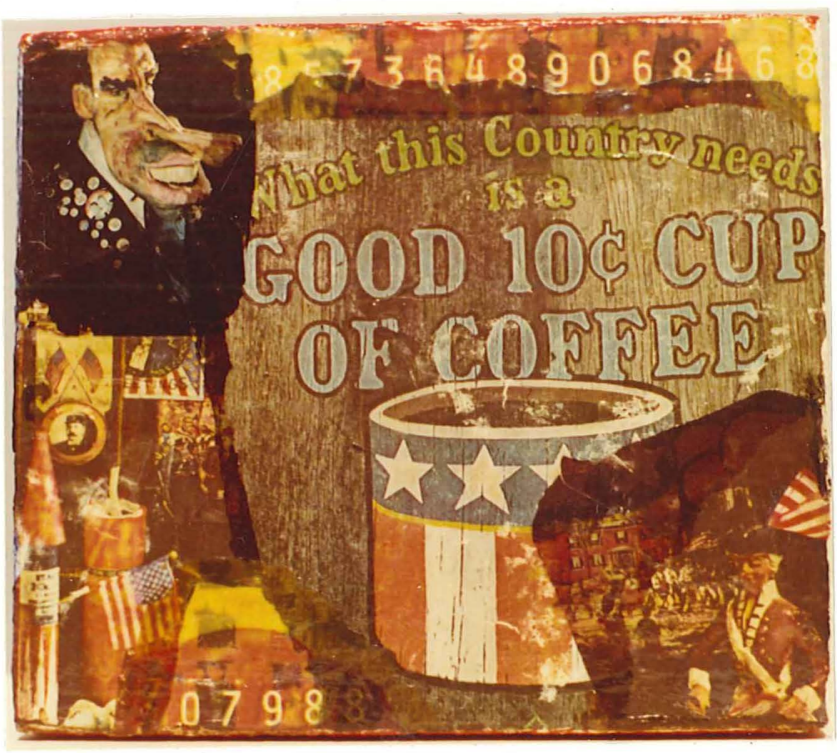


Monoprinting

Monoprinting can be a fine introductory experience in printmaking. The acrylic color, thimed with a small amount of medium and water, is rolled onto a flat nonabsorbent surface such as glass, Formica, Masonite or heavy cardboard coated with polymer medium. Work the design into the inked plate with a brush, knife or other tool. Cut or torn paper may be used as blockout for shapes in the design. When the design is complete, place the paper for printing over the plate and rub gently. The paper can be dampened and blotted before printing, is desired. Peel the paper off the piate at once and lay it out to dry. Water dripped into the color on the plate will make an interesting pattern. Multicolor prints can be made by reinking and redesigning the plate. Transparent color runs can be combined with opaque. Monoprints can be done on a heavily crayoned paper for rich and colorful effects.

In another monoprinting method the paper is placed over an inked plate and drawn upon with a tool. The ink will adhere to the paper wherever the pressure is applied. Monoprinting can be used in conjunction with painting. The plate for this should be either flexible, as oilcloth, or lightweight. The design is worked out on the plate in the manner of the monoprint. When the design is ready to print, press the inked surface against the surface of the 
painting and transfer the design to the painting.

Collograph

A collograph is a print from a collage like surface, inked and printed as a linoleum block. It should be built on a rigid surface, following collage construction techniques but avoiding high relief or sharp edges as these will not print satisfactorily. Paper, cloth, screening and string are suitable. If granular naterials are used, shake off the excess and seal with medium. After the plate is complete, coat it with one or more coats of polymer medium, allowing it to dry thoroughly before inking and printing.

\section{Silk Screen}

It is my feeling that the most valuable contribution the synthetic medium can make to the silk screen process is as a block-out material. It dries rapidly, is waterproof when dry and can be removed from the screen either by washing with soap and water with a brush, or with the acrylic remover.

In the photographic silk screen process, the black acrylic can be used for the design on the acetate sheets, as it adheres well to acetate film.

\section{Raised Design on Block}

This technique involves building an extruded line on a heavy cardboard or Masonite plate with modeling paste. 
For a line design, the paste can be squeezed from a bottle. The paste can also be worked into shapes directly on the plate, avoiding high relief. After the paste has set up, it can be inked, wiped and printed in the usual manner.

\section{Corrections}

Modeling paste can be used to correct exrors in linoleum or wood blocks simply by filling in the area to be change, allowing the paste to dxy completely and recutting.

\section{DRAWING WITH ACRYIICS}

Acrylics can be used to supplement the usual pen and pencil methods as well as to enhance work done in the graphic media.

\section{Ink}

Acrylic color may be diluted with water and used as ink. Black, umbers and siennas are particularly good for this. Apply the ink with pen, brush or handmade drawing tool.

Inks and dyes may be made waterproof through the addition of polymer medium.

\section{Wet-on-Wet}

Use a good quality drawing or water color paper. Brush on a background wash of transparent polymer medium, clear or colored. While the ground is still damp, draw on it with a brush charged with color. The color will 
bleed into the still damp background.

\section{Iinseed Oil Resist}

Iinseed will resist the water base acrylic colors. To a mixture of acrylic color and polymer medium add linseed oil. The mixture should be of a consistency which will flow from a reed pen or other drawing tool. A line drawing done with this mixture will be interesting, as the line will be lost in some places as the oil resists the color.

\section{Ink Wash}

Using fluid acrylic paint, do a free brush drawing on heavy paper. Fill most of the area, some can be quite detailed, some just washed with color and some left untouched with color. When the color has dried, brush diluted India ink over the entire surface. The ink can then be washed off the acrylic covered areas, but will have affected the tone of the drawing and will remain wherever it came into direct contact with the uncoated paper.

\section{Fixative And Wash}

Polymer medium or varnish can be diluted with water and used as a fixative for graphic media and water paints. The solution can vary in proportions from a one to one mixture to one part medium to three parts water. It is suggested that a little experimentation will help in deter- 
mining just the proper mix. The mixture can be brushed or sprayed.

In adaition to its use as a clear fixative, the polymer medium and water mixture can be colored with acrylic paint and applied over a drawing as a colored wash. The solution should be kept transparent.

A drawing can be glazed with medium or varnish mixed with a small quantity of white paint. The glaze must be kept transparent, and can be applied in more than one coat if desired. For a special effect, the lines of the drawing can be totally obscured in some areas.

\section{MOSAIC}

The making of a mosaic of acrylic-cement tiles could be a classroom project which permits involvement of students in several different areas of craftsmanship. The tiles are made by the students. To do this, polymer medium is mixed with cement and small amounts of water and worked into a paste which pours or spreads easily. Shape this mixture into individual tiles if desired, or pour it into a sheet on a non-absorbent surface. The sheet can be scored before the paste sets up and when hard the tiles can be broken apart. The tiles can be sawed with a serrated edge tool if the cement has dried.

Acrylic color can be blended into the original mixture; the tiles can be glazed by dipping them into a liquid mixture 
of color or they can be painted individually.

Modeling paste or acrylic gel can be used to adhere the tiles to a sturdy support. Apply the adhesive to both the support and the tiles, press the tiles into the ground adhesive and let dry. Coat the finished mosaic with one or two coats of polymer medium or varnish.

The directions for a transparent mosaic are given in section $v$.

V. TRANSPARENT AND TRANSIJUENT DESIGN TEGHNIQUES

The clarity of the polymer mediuns makes thern ideal for experimental work in transparent and transiucent design. Acetate, cellophane and the plastic films are useful for these projects, as well as Plexiglas, glass and sheets of hard plastic.

Unusual effects can be achieved by laminating colored cellophane in sheets and shapes of varying sizes to transparent backing with polymer medium. The laminating process can be repeated with various colors until the design is completed. In some areas the student might paint opaque designs with acrylic color.

Colored tissue, cellophane or sheets of hardened, colored polymer medium can be laminated between two layers of polymer medium. Pour the medium into a prepared form. This can be heavy aluminum foil shaped to form a shallow pan, a cardboard box lined with plastic wrap, or dikes of 
clay formed on a non-absorbent surface. When the medium has set up, the layers of color can be applied to the backing with a light coat of polymer medium. Over this pour another layer of the emulsion and let it dry thoroughly before removing it from the mold. This can be mounted on glass, Plexiglas or heavy acetate, framed, if desired, and hung where the light comes through it. Instead of laminating the sheets of colored matexial between layers, a design can be painted, squeezed or dpipped onto the first sheet and the second layer of film applied over this when it dries.

If any difficulty is experienced in removing the sheets of poured plastic from the non-absorbent backing, they can be loosened in water.

A transparent mosaic can be done on acetate, plastic or glass. Tiles are made by mixing color with enough polymer medium to pour well. Control the shapes by preparing forms as in the previous project. These can be poured into individual forms rather than sheets. However, sheets are easily cut into smaller shapes. If clay is used for dikes, it can be rolled with a rolling pin and cut into strips to assure an even edge on the form. A dike can also be formed by cutting strips from a hardened sheet of medium. After the transparent tiles have set up completely, they can be adhered to the backing with a thin coat of polymer medium. 
VI. MISCELLANEOUS CIASSROOM USES

Sculptural Medium

Both modeling paste and polymer medium can be useful in sculptural work. Both can be mixed with aggregate such as Perlite or Vermiculite, or with plaster or cement. Modeling paste alone can be used for modeling, but some of the water must be allowed to evaporate before it will hold its shape.

In adition to being used as a modeling material, the medium and aggregate mixture can be cast into a mold or be allowed to harden and be carved. It can be sawed, cut, chiseled, filed and polished when hard. The liquid mixture of medium and aggregate can be poured into a carton such as a milk carton and allowed to harden for use as a block for carving.

When it is used in a manner similar to clay, it is more economical, and the form will dry more rapidly, if an armature is used. Depending upon the nature of the work, the armature can be of styrofoam, papier mâché, twisted paper, wood, wire or other material. When building up a form and adding additional layers of medium to a dry sculpture, the form should be dampened before the new application is made. A complete bond between layers is formed if this is done.

Color can be mixed with the material before the sculpture is started; the final sculpture may be polished 
by buffing or painted with acrylic paints or glaze. The sculpture should be sealed with polymer medium before painting or glazing.

Polymer mediums have a great deal more extensive possibilities as a sculptural medium than is dealt with in this paper. More information on this usage can be obtained from the books listed in the bibliography.

Terra cotta and other clay sculptures can be finished very effectively with a coat of polymer paint or glaze.

\section{Papier Maché}

Polymer medium, gel or modeling paste can be used as the adhesive in papiex mâché. However, if large quantities are to be used, it is somewhat expensive. It does have the advantage of drying much more rapidly than wheat paste. The pulp can be handled in the usual way and the finishing layers of paper applied with acrylic medium for a smoother surface.

A crumpled paper or other type of dry center will facilitate the drying of forms. Crushed aluminum foil makes an ideal center form around which to build. Iarge forms and especially appendages should have an inner form of wire or wood for strength.

If a smooth surface is desired on the finished form, it can be brushed with several coats of gesso or modeling paste. Modeling paste can also be used to construct details 
on a form. Use acrylic paint to paint the finished work and control the sheen by use of gloss or matte medium or varnish.

\section{Picture Frames}

Gesso and modeling paste are useful in picture frame perparation and repair. They provide an excellent ground for gilding and can be textured.

Damaged frames can be repaired with modeling paste or gesso. It can be shaped or carved to match the existing design of a frame.

\section{Slides}

Thinned acrylic color can be used in making slides on glass or acetate for projection. The color must be kept fairly thin as it becomes opaque when thickly applied. 
CHAPTER V

CONCLUSIONS

In making this study of the use of acrylics in the classroom. I have come to the conclusion that we are onl.y beginning to realize their possibilities.

Acrylics free the student-arist from many of the inhibiting technical limitations and problems of other media. This freedom can lead to a new creativity in the classroom approach to art, expanding the horizons of both student and teacher. Because of its workability and ease of application, the student can go from transparency to opacity, from smooth surface to textured, from the simple to the complex, with ease. Expression need not be limited to old forms and techniques but through a discovery approach the classroom can become an exciting place where synthetic materials are manipujated and combined in mixed media experiences which were impossible before.

I do not think that acrylics will supplant traditional media nor will their survival be based on their use as substitutes for them. They are so compatible with the searching and changing forms of contemporary art that they have already exerted an influence upon it. Just as the discovery of a new medium in the past gave new directions to painting, the 
acrylic medium may exert a strong influence upon the art of the future.

Through a proper introduction, with explanation and demonstration on the part of the teacher, an exciting relationship can be established between the student and the synthetic medium. The usual pitfalls can be avoided by taking a little time to explain the working characteristics and the pecularities or acrylics. I worked with youngsters from nine to sixteen years of age with acrylics and we experienced very little trouble with the fast drying medium.

our acrylic experiments were designed as an introduction to painting, as well as to acrylics. Some of the students involved had a little oil painting experience, some of them only a minimum of gxade school painting experience with tempera and water color. For all it was a first experience with acrylics.

The students were excited with their adventures in color mixing. Even the third graders did a painting in which them mixed their own colors on the palette using only the polymer medium and liquid colorants. Before they began to paint they gathered around a worktable for a short demonstration of the mixing process with an emphasis on the potency of the colorant, and this was sufficient.

They did a value experiment using only the acrylic house paint in charcoal gray or black and white. Some impressive abstract value studies resulted. 
They did texture blocks using only a nail and a cardboard comb which they cut out themselves, as the texturing tools.

The blocks demonstrated an inventive and creative use of texture and pattern. I feel that this step by step building of a foundation with the elements of painting can lead to a sensitive and personal approach to painting.

As for student reactions, a few comments are recorded heres

"I like acrylics better than oil and water color because it does not run, and I think you can do more things with it, like express a feeling better. I think there is no comparison, acrylics are much better."

"I like acrylics better because they are easjer to thin than oils. I like them better than water color because with water color the colors run together more. The acrylics rub off your skin, you can paint over something else with them and you can wash it off with water."

"They have many advantages--drying faster, you can cover more easily."

"I like the way they $\operatorname{mix}$ weIl. You can get quite a variety of colors mixing. Oils aren't transparent and acrylics can be. I like the way it dried fast on your board because you can cover up sooner."

"Acrylic is like water color but better because it's thicker and more fun. I like everything but having to keep 
putting the lids back on!"

The only complaints expressed were of the nature of this one: "If you get some on your clothes, you're stuck, and it sometimes dries on the palette."

From my experiences with acrylics, in the studio and in the classroom. I conclude with the proposal that they can and should play an integral and important part in the teaching of painting and other art techniques, and that through a controlled, experimental, discovery approach, acrylics have a significant contribution to make in the school art curriculum. 


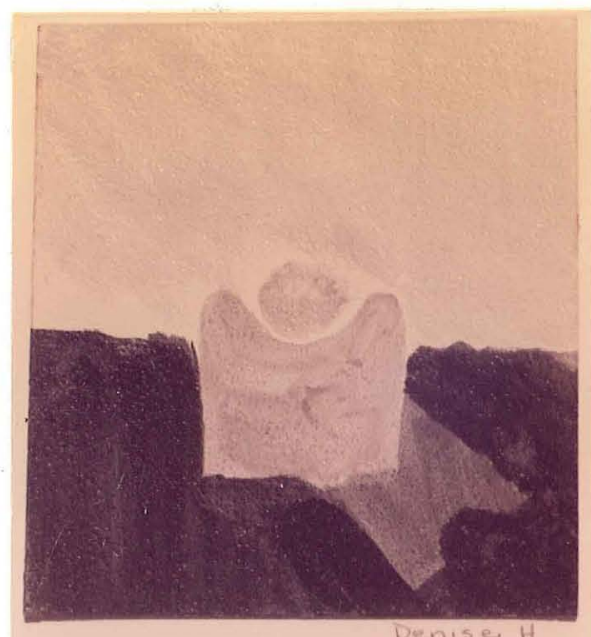

Figure 7. Value study $6^{11} \times 7^{57}$ Denise Hoskins polymer medium with colosant.

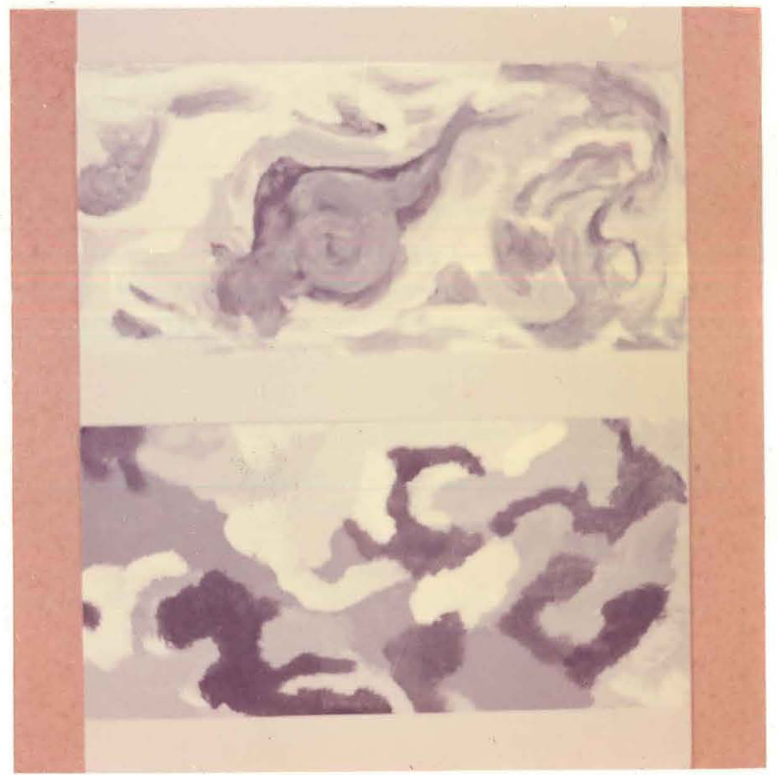

Figure 8. Value studies $9 " \times 18$ " Top: Steven Karlik

Bottoms Denise Hoskins

Acrylic latex with polymer medium 


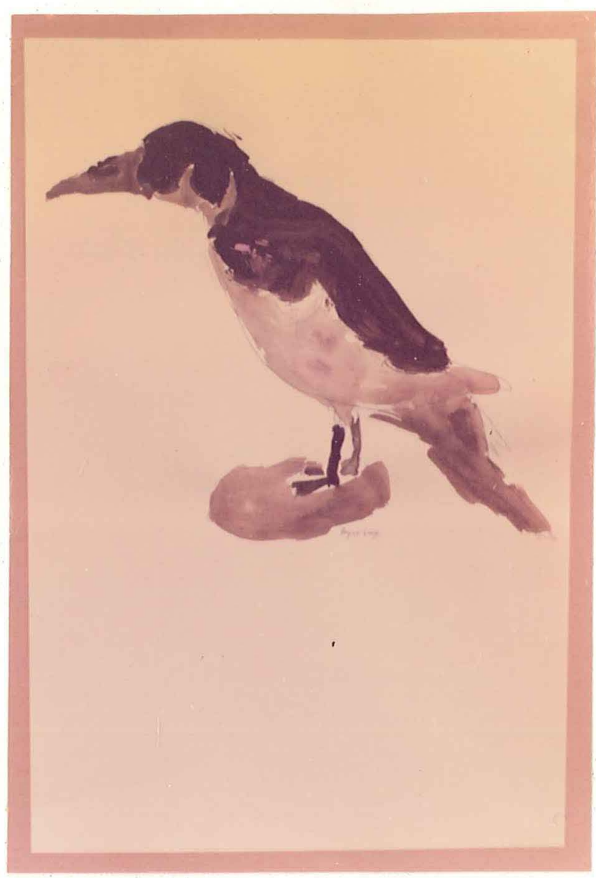

Figure 2. Transparent Color $14^{\circ 0} \times 17^{\circ 0}$ Roger Iong

Acrylic latex and colorant

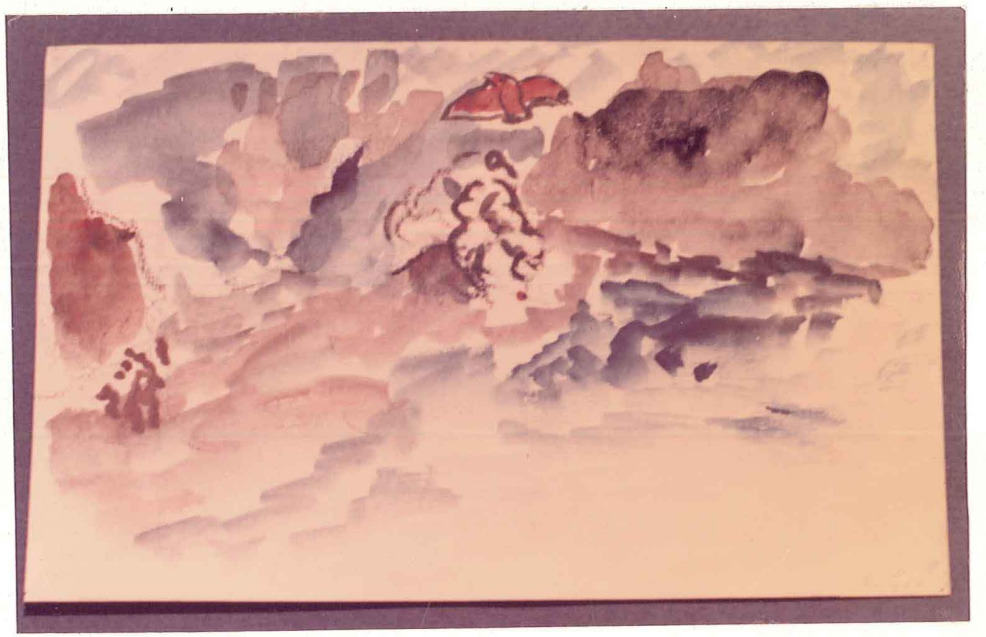

Figure 10. Transparent Color $6^{\circ 0} \times 9^{\circ 0}$ Roger Long Polymer medium and colorant 


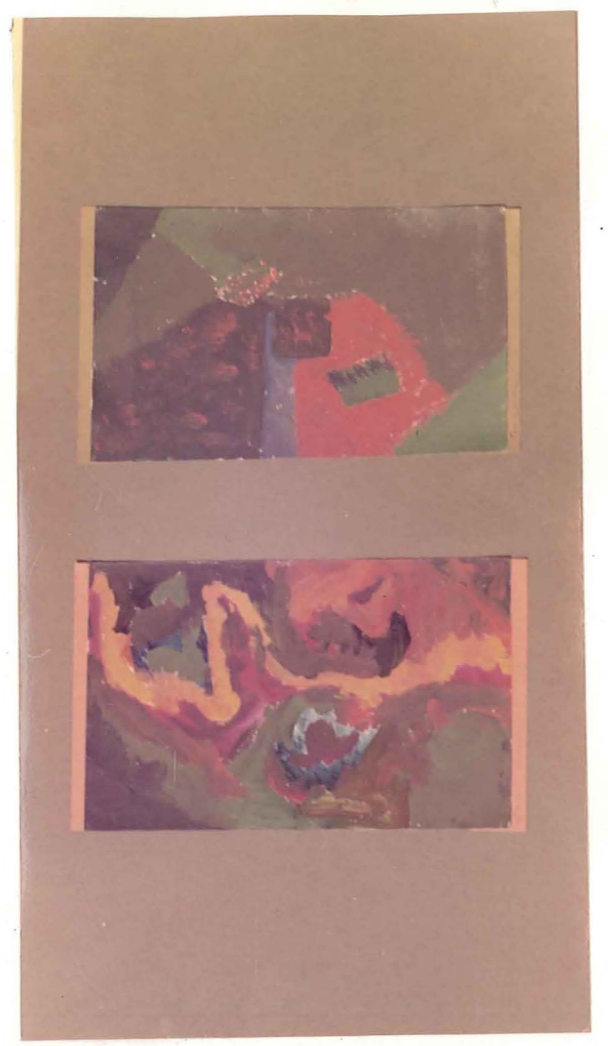

Figure 21. Opaque Colos: pop: rom schjerhol\% Bottom: Steven Karlik Polymer medium with colorant

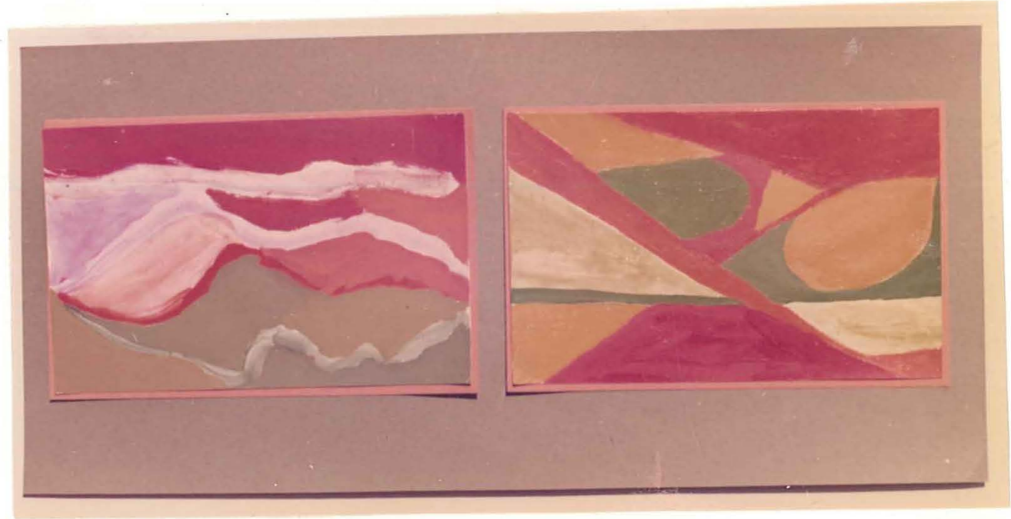

Figure 12. Opaque Color 6" $6^{\prime \prime}$ Lefts Mimi Brodeur Right: Iisa Jennings

Polymer mediun with colorant 

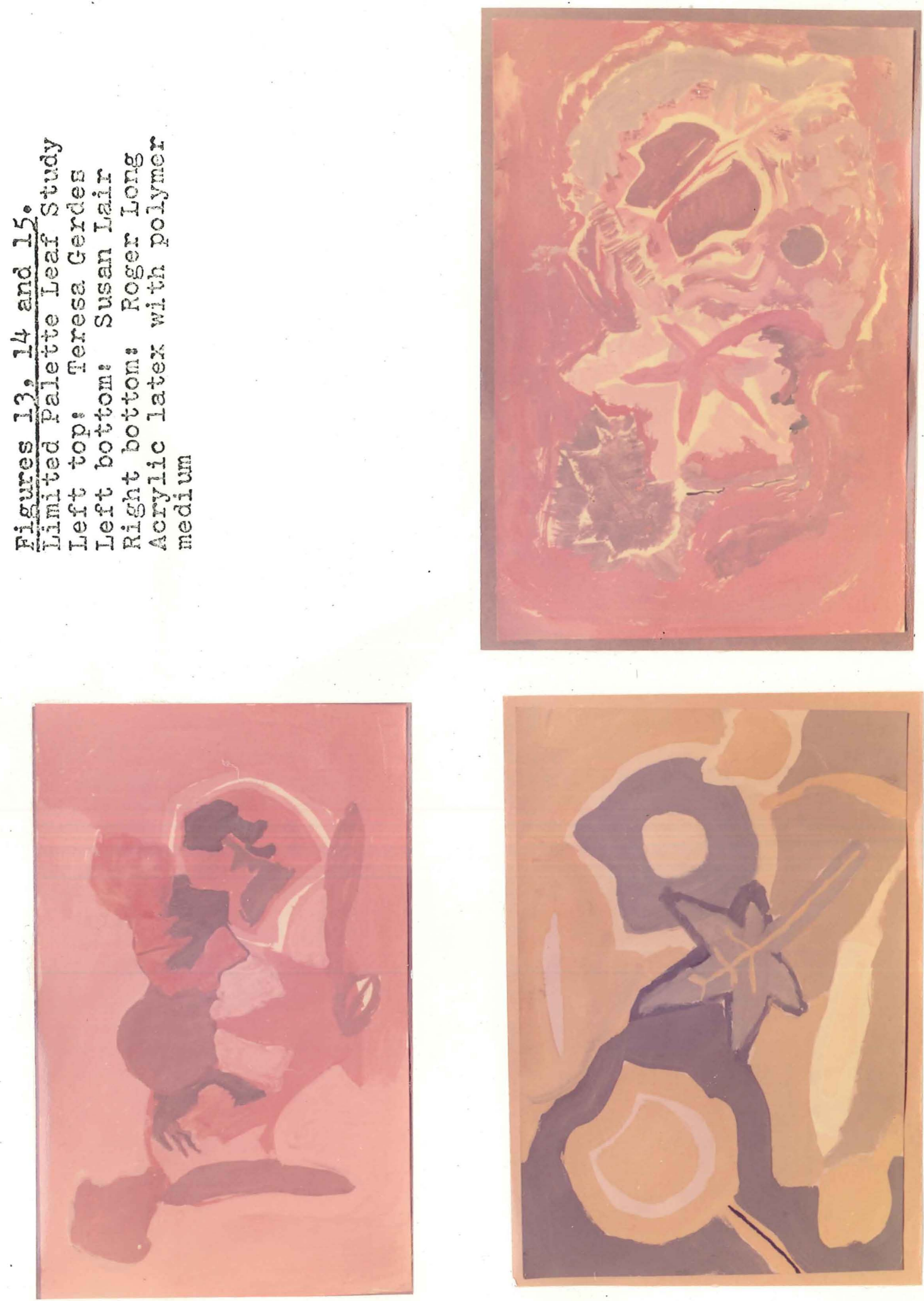


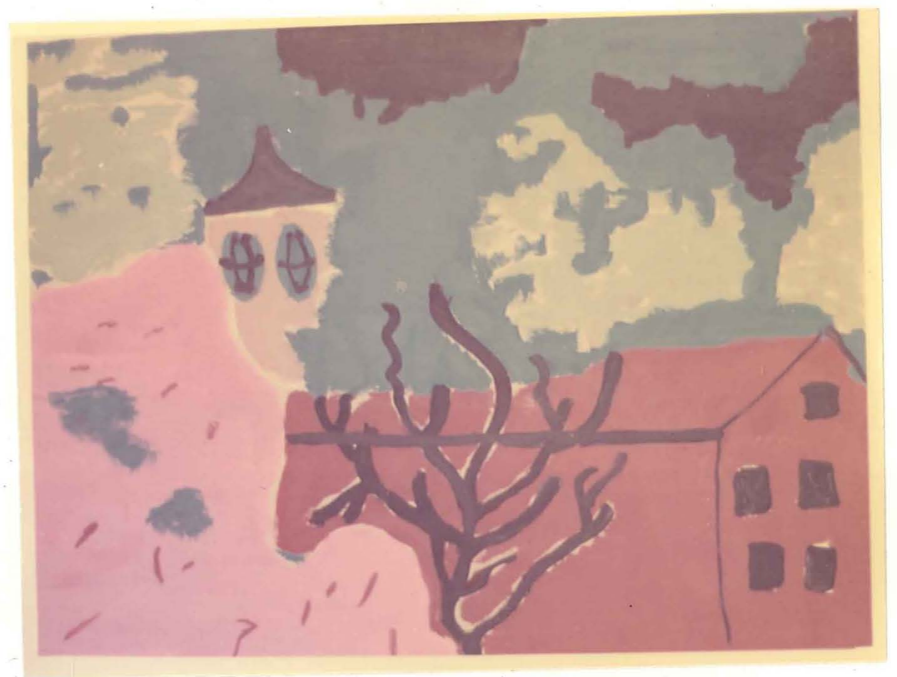
Figure 16. Acrylic Jandscape $18{ }^{\prime \prime} \times 22^{\prime \prime}$
cathy Polioch Later with colorant

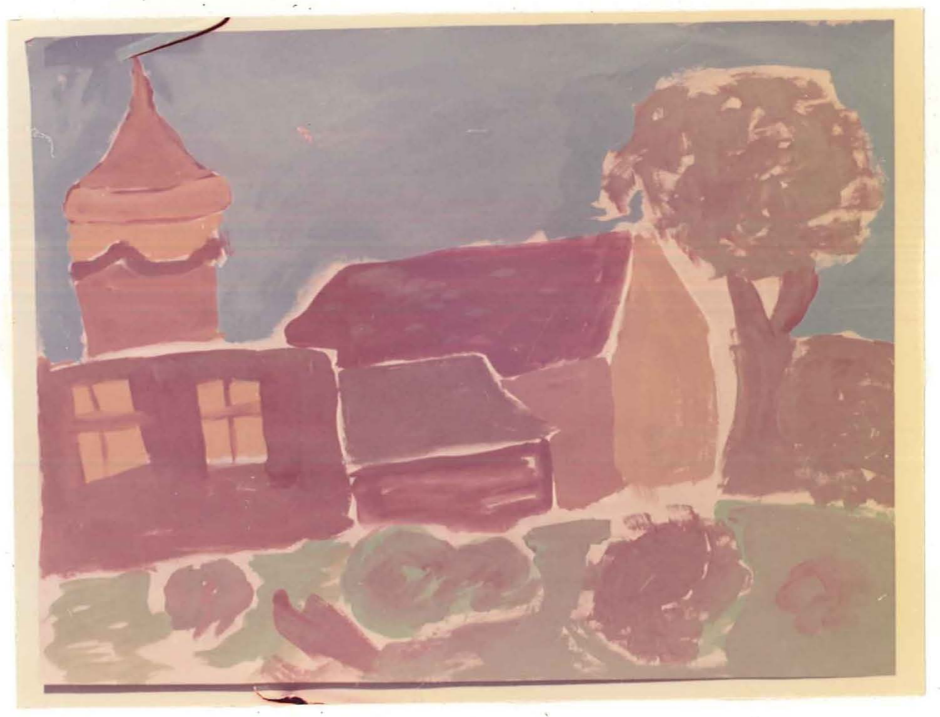

Figure 17. Acrylic Landscape 18" $\times 22^{\prime \prime}$ Cathy Pinch Latex with colorant 


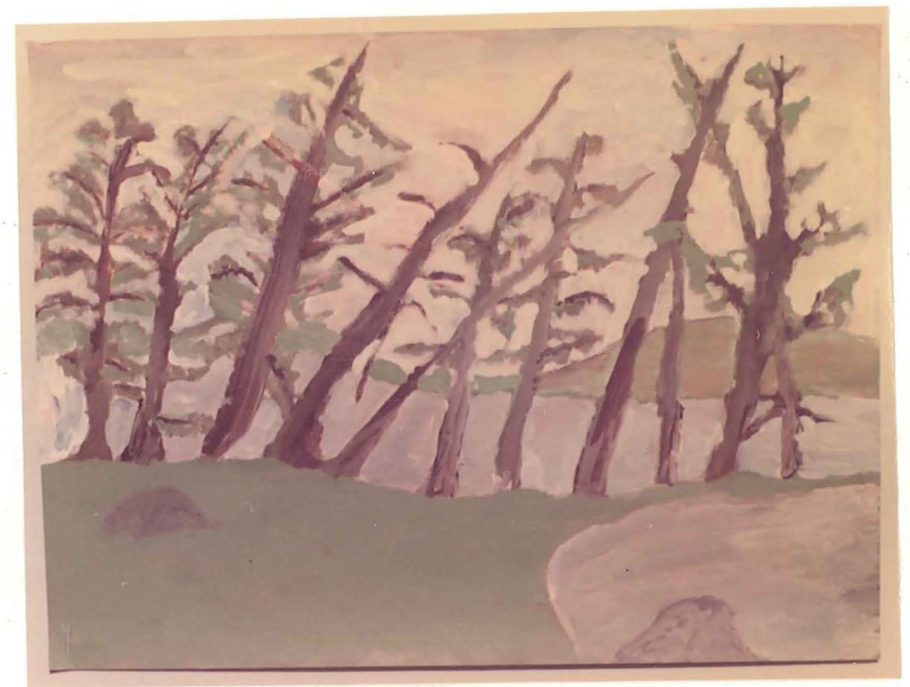

Figure 18. Acrylic Landscape $18^{\prime \prime} \times 22^{\prime \prime}$ Steven Karlik Iutex with colorant

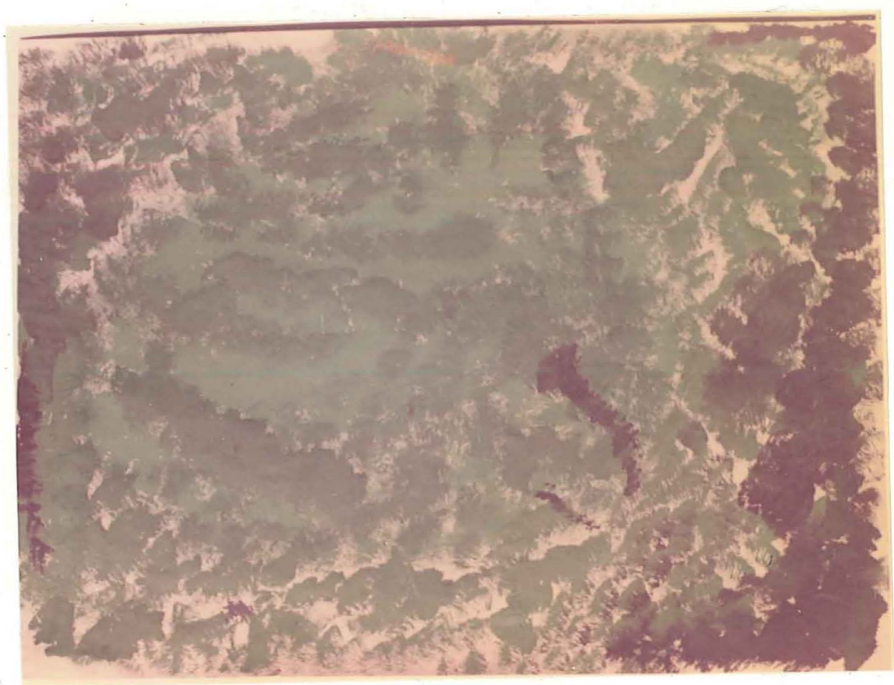

Figure 19. Acrylic Landscape $18^{\prime \prime} \times 22^{\prime \prime}$ Denise Hoskins Latex with colorant 


\section{A SELECIED BIBIIOGRAPHY}

Brooks, Leonard. Painting and Understanding Abstract Art. New York, 1964.

Chavatel, George. Exploring with Polymer Media. New York, 1.966.

Fabri, Ralph. Guide to Polymex Painting. New York, 1966.

Gutiérrez, Jose and Nicholas Roukes. Painting with Acrylics. New York, 1966.

Jensen, Lawrence N. Synthetic Painting Media. Englewood Cliffs, N. J., I964.

Torche, Judith. Acrylic and Other Water-Base Paints for the Artist. New York: 1967.

Woody, Russell 0., Jr. Painting with Synthetic Media. New York, 1965. 
APPENDIX 
A PARTIAL IIST OF LOCAI SUPPLIERS

PRODUCT

Acrylic artists' products Art--Pak

8106 N. Denver

Portland, Oregon

J. K. Gill Co.

408 S. W. 5th Avenue

Portiand, Oregon

Lake Oswego Art Center

$430 \mathrm{~N}$. State Street

Lake Oswego, oregon

Roger Iong Gallery

Lake Oswego, Oregon

Portland State Bookstore

531 s. W. Hall street

Portland, Oxegon

Shaninon \& Co.

$403 \mathrm{~S}$. W. 10th Avenue

Portland, Oregon

Villa Mart

Portland, Oregon

Acetate film

Acetone, alcohol

Acrylic house paint

Additives, vermiculite, perlite

plaster of

Paris

cement

Art, architect and engineering supply stores

Paint store

Building supply store

Colorants

Lumber, paint or hardware store 
PRODUCT

Fiberglass cloth and resin

Plastics, sheet and resin

Wood products

\section{SUPPIIER}

Plastic supply store, boating supply store

Multi Craft, Ince

$5940 \mathrm{~N}$. Interstate

Portland, Oregon

Tap Plastics, Ine.

720 S. E. Sardy BIvd.

Portland, Oregon.

Lumber or building supply store. 
MANUFACTURERS OF ACRYIIC ARTISTS' PRODUCTS

\author{
BRAND \\ MANUFACTURER \\ Aqua-Tiec \\ Bocour Artist Colors Incorporated \\ 552 W. 52nd Street \\ New York, New York 10019 \\ Craftint \\ Craftint Manufacturing Co. \\ 18501 Euclid Avenue \\ Cleveland, Ohio 44112 \\ Hypl.ar \\ M. Grumbacher, Inc. \\ 460 West 34 th street \\ New York, New York 10001 \\ Iiquitex \\ Permanent Pigments, Inc. \\ $2700 \mathrm{Highland}$ Avenue \\ Cincinnati, Ohio 4.521\% \\ Politec \\ Politec Company \\ 425 Fourteenth Street \\ San Francisco, California 94103 \\ Reeves \\ Stafford Reeves Incorporated \\ 626 Greenwich Street \\ New York, New York 10014 \\ Shiva \\ Shiva Artist's Colors \\ Shiva-Rhodes Building \\ 10th and Monroe Streets \\ Paducah, Kentucky 42001 \\ Vanguard I : New Masters Fine Arts Division \\ Hunt Manufacturing Company \\ 1405 Locust Street \\ Philadelphia. Pennsylvania 19102 \\ Weber \\ F. Weber Company \\ 1220 Buttonwood Street \\ Philadelphia, Pennsylvania. 19123.
}




\section{THESIS PAINTINGS}

The paintings in these photogiaphs as well as all other work shown, were done with acrylics. In some in. stances the acrylje was conbined with other media in processes described in the text. All student work showr was done in the Saturday Axt Class at Marylnurst Coliege during 1969 and 1970. All work not attributed to individual students was done by the author.

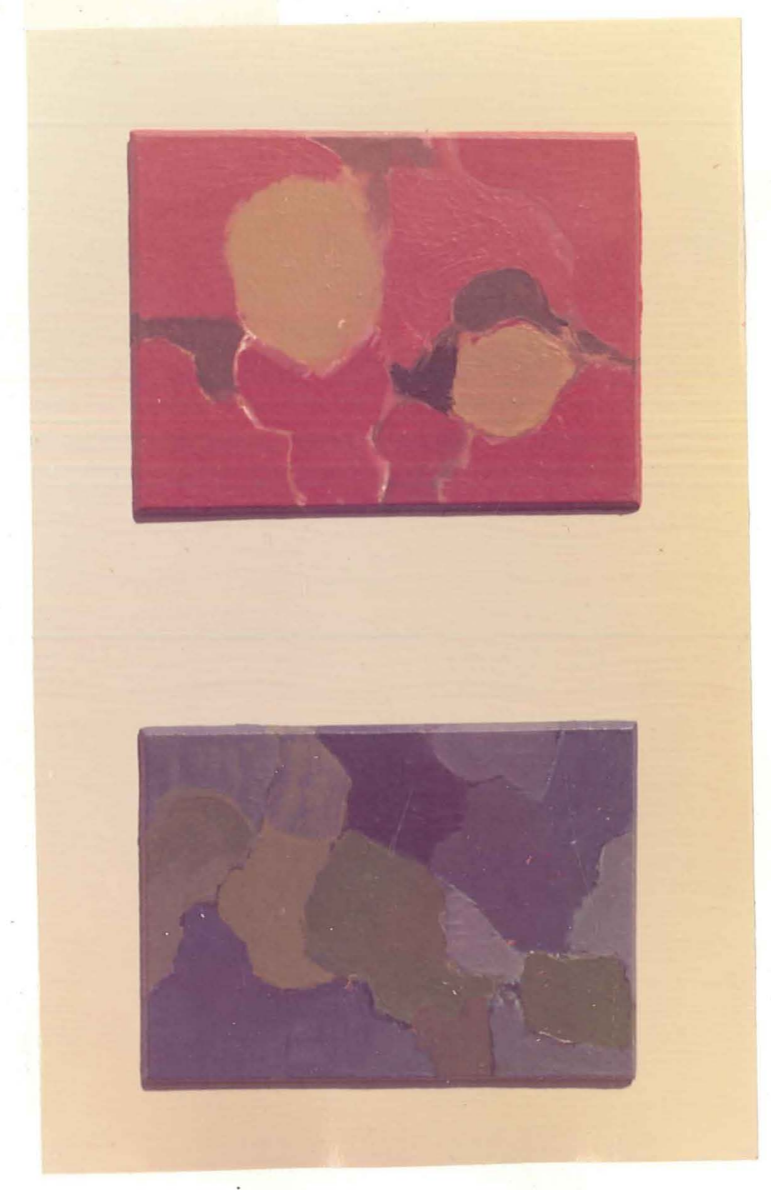

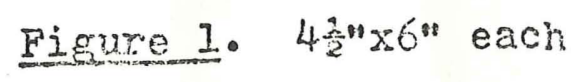




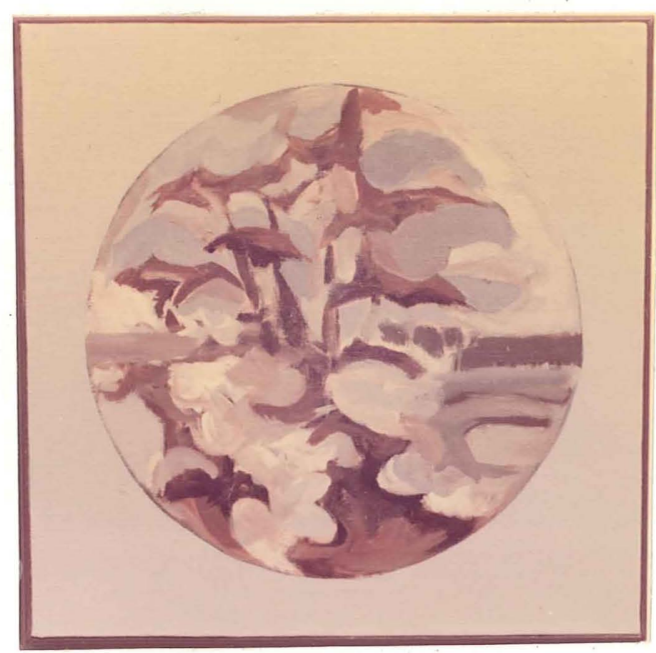

Figure 2。 200 $\times 20^{\circ 1}$

Figure 3. $40 " \times 30 \%$

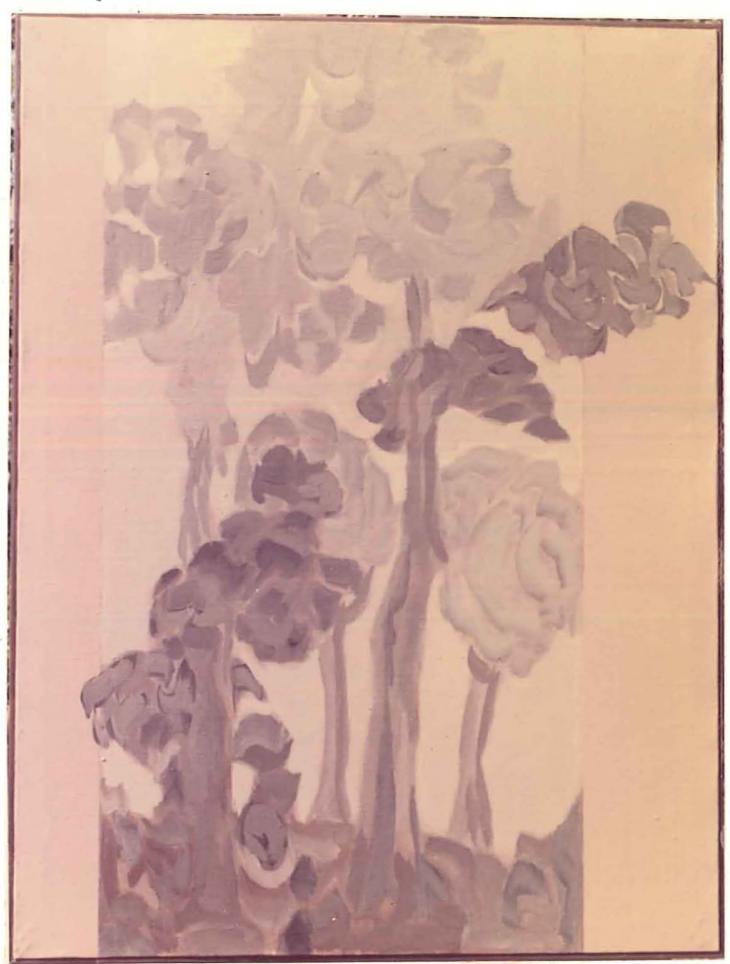




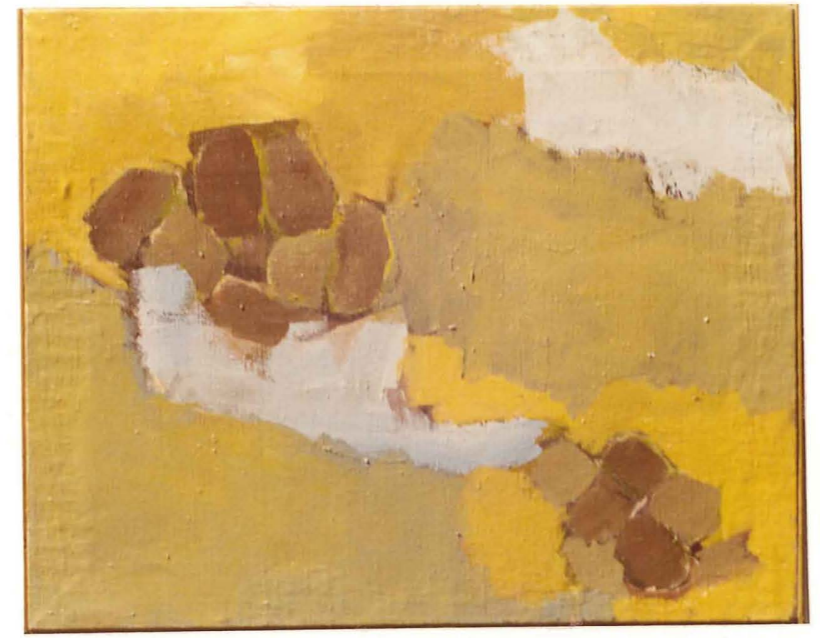

Figure 4. $16^{\prime \prime} \times 20^{\prime \prime}$

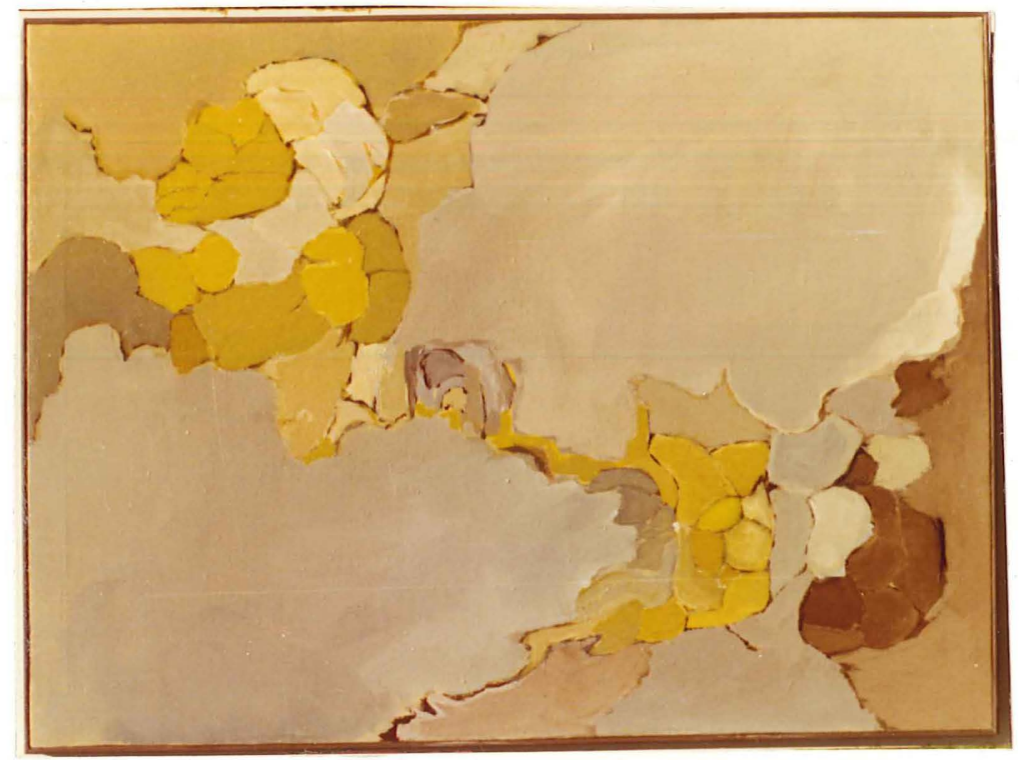

Figure 5. $300^{\circ} \times 0^{\circ}$ 
$\frac{2 j g u e 6}{180 \times 20^{\circ}}$

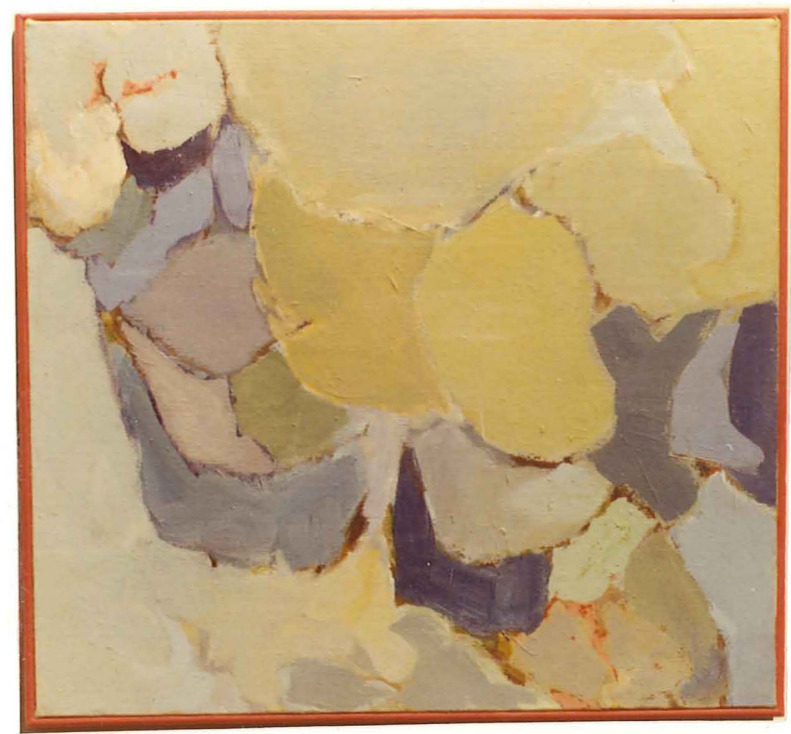

$\frac{\text { Figuse } 2}{12^{\circ} \times 16^{11}}$

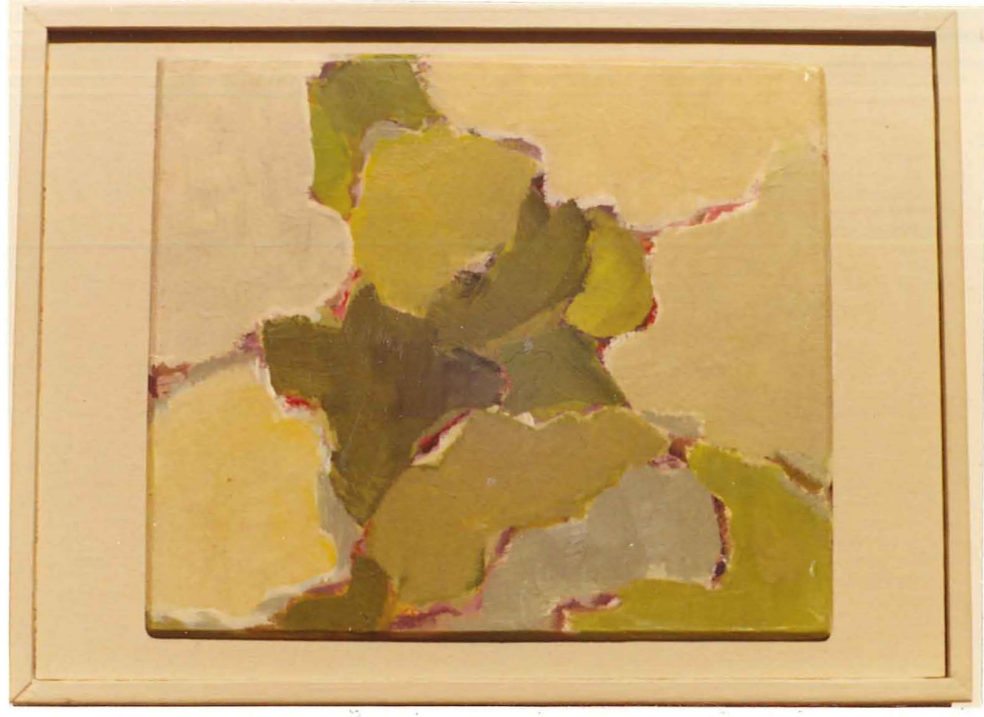


$\frac{\text { Figure } 8}{9+1010 \frac{11}{2}}$

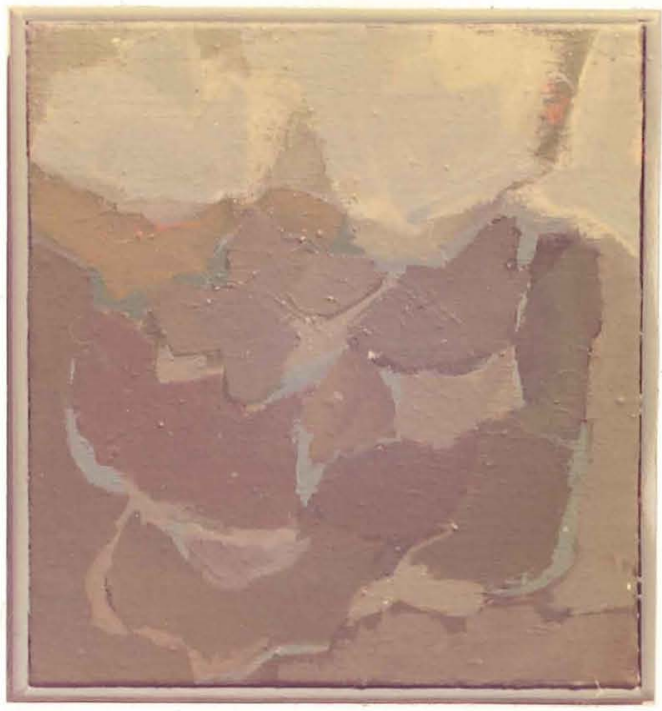

$\frac{\text { Figure } 9 .}{10^{\prime \prime} \times 22^{10}}$

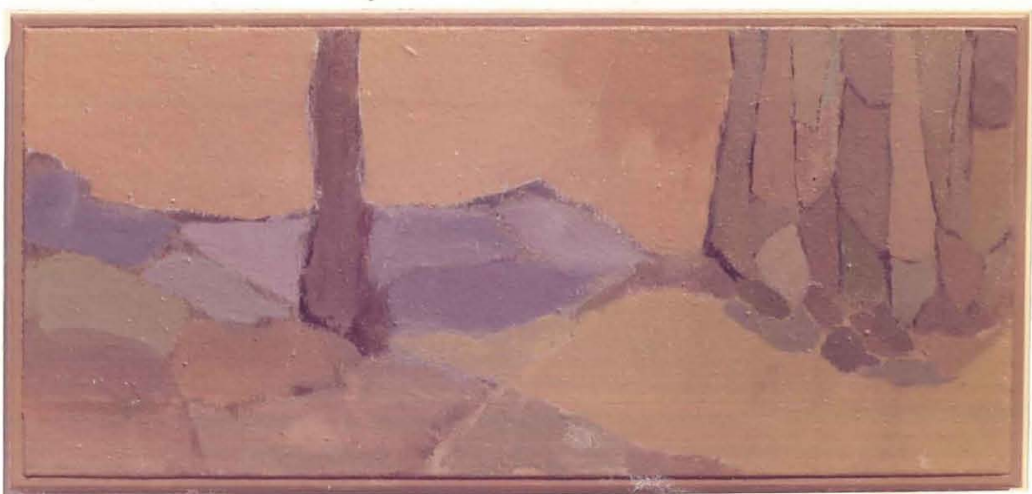

$\frac{\text { Figure } 10}{10^{10} \times 22^{60}}$

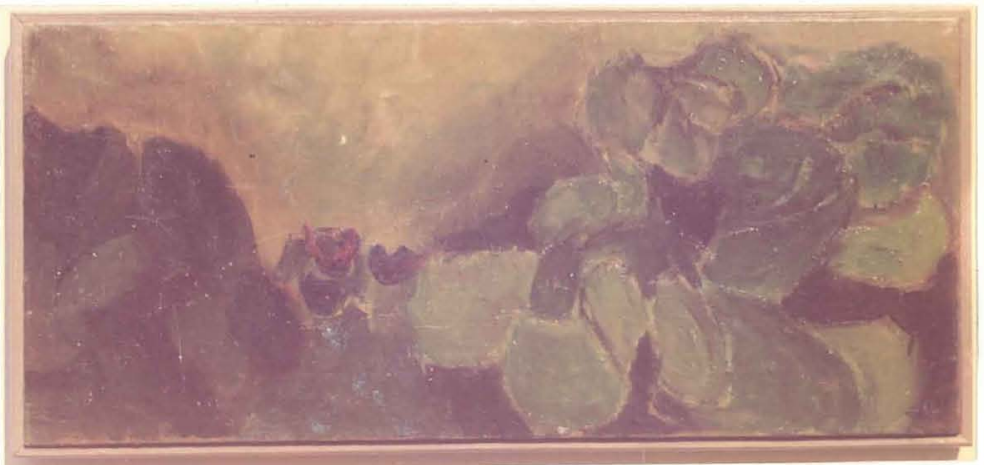


61

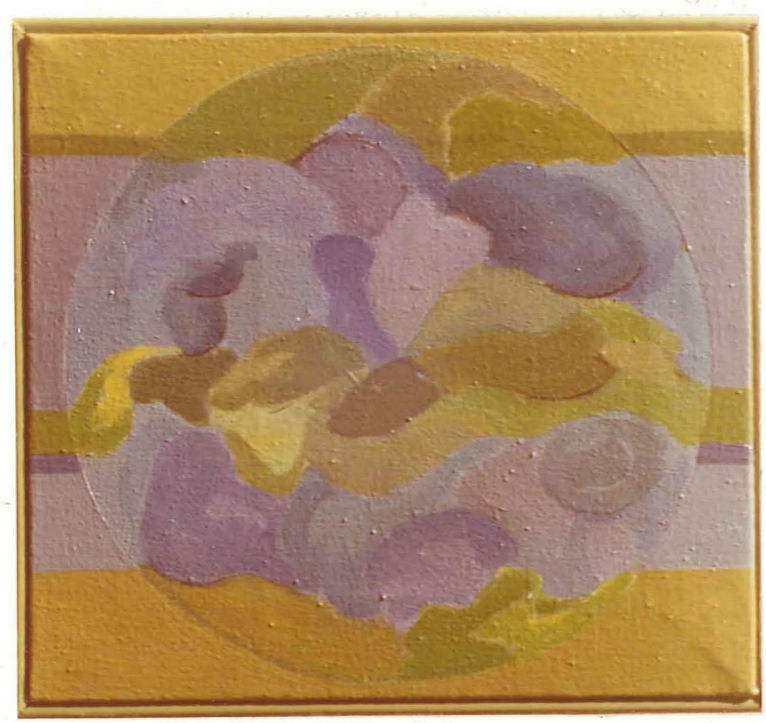

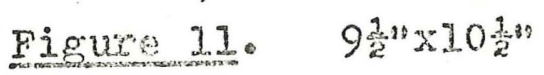

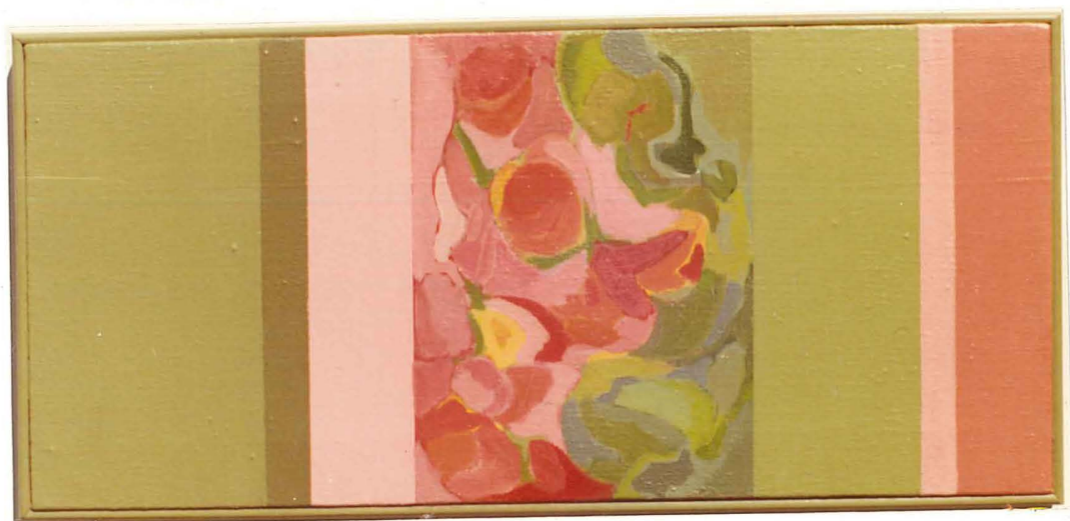

Figure 12. $\quad 10^{\prime \prime} \times 22 "$ 


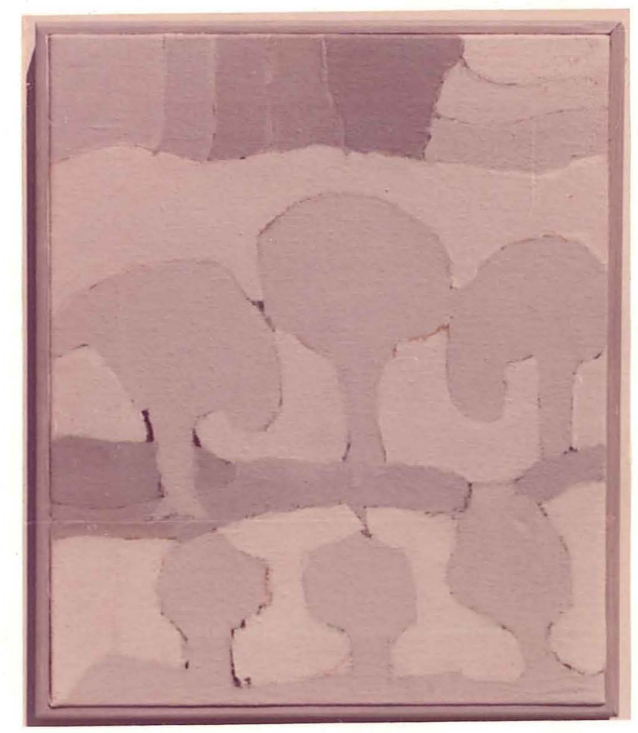

Figure 13. $\quad 12^{\prime \prime} \times 15^{\prime \prime}$

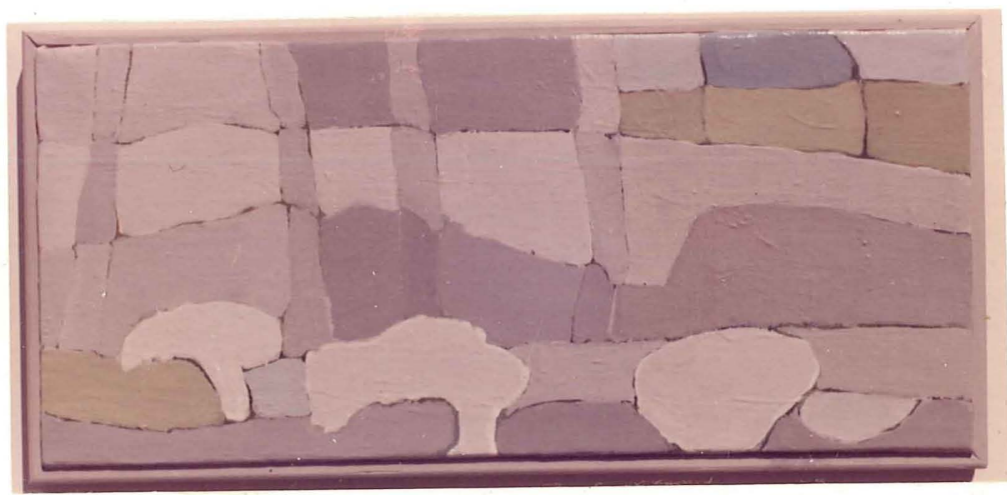

Figure 14. 9"x18" 